\title{
The Retinal Pigment Epithelium: Something More than a Constituent of the Blood-Retinal Barrier-Implications for the Pathogenesis of Diabetic Retinopathy
}

\author{
Rafael Simó, Marta Villarroel, Lídia Corraliza, Cristina Hernández, \\ and Marta Garcia-Ramírez \\ CIBER de Diabetes y Enfermedades Metabólicas Asociadas (CIBERDEM), Instituto de Salud Carlos III (ISCIII), \\ Unitat de Diabetis i Metabolisme, Institut de Recerca Hospital Universitari Vall d'Hebron, Passeig Vall d'Hebron 119-129, \\ 08035 Barcelona, Spain \\ Correspondence should be addressed to Rafael Simó, rsimo@ir.vhebron.net
}

Received 29 June 2009; Revised 28 September 2009; Accepted 16 November 2009

Academic Editor: Karl Chai

Copyright () 2010 Rafael Simó et al. This is an open access article distributed under the Creative Commons Attribution License, which permits unrestricted use, distribution, and reproduction in any medium, provided the original work is properly cited.

The retinal pigment epithelium (RPE) is an specialized epithelium lying in the interface between the neural retina and the choriocapillaris where it forms the outer blood-retinal barrier (BRB). The main functions of the RPE are the following: (1) transport of nutrients, ions, and water, (2) absorption of light and protection against photooxidation, (3) reisomerization of all-trans-retinal into 11-cis-retinal, which is crucial for the visual cycle, (4) phagocytosis of shed photoreceptor membranes, and (5) secretion of essential factors for the structural integrity of the retina. An overview of these functions will be given. Most of the research on the physiopathology of diabetic retinopathy has been focused on the impairment of the neuroretina and the breakdown of the inner BRB. By contrast, the effects of diabetes on the RPE and in particular on its secretory activity have received less attention. In this regard, new therapeutic strategies addressed to modulating RPE impairment are warranted.

\section{Introduction}

The retinal pigment epithelium (RPE) is a monolayer of pigmented cells situated between the neuroretina and the choroids. The RPE is of neuroectodermal origin and is therefore considered to be part of the retina. The apical membrane of the RPE faces the photoreceptor's outer segments and its basolateral membrane faces Bruch's membrane, which separates the RPE from the fenestrated endothelium of the choriocapillaris (Figure 1). The RPE constitutes the outer blood-retinal barrier (BRB). The inner BRB is mainly constituted by endothelial cells. Tight junctions between neighbouring RPE cells and neighbouring endothelial cells are essential in the strict control of fluids and solutes that cross the BRB as well as in preventing the entrance of toxic molecules and plasma components into the retina. Therefore, this sealing function is essential for the integrity of the retina [1].
The main functions of the RPE are the following: (1) Transport of nutrients, ions, and water (2) absorption of light and protection against photooxidation, (3) reisomerization of all-trans-retinal into 11-cis-retinal, which is a key element of the visual cycle, (4) phagocytosis of shed photoreceptor membranes, and (5) secretion of various essential factors for the structural integrity of the retina.

Apart from these functions, the RPE stabilizes ion composition in the subretinal space, which is crucial for the maintenance of photoreceptor excitability [2]. In addition, the RPE contributes to the immune privileged status of the eye as part of the BRB and by the secretion of immunosuppressive factors inside the eye. In recent years it has become clear, mainly from in vitro studies, that RPE cells play an important role in immune responses by the expression of major histocompatibility complex (MHC) molecules, adhesion molecules, FasL and cytokines [3]. With these different complex functions, the RPE is essential for 
visual function. A failure of any one of these functions can lead to degeneration of the retina, loss of visual function, and blindness.

Diabetic retinopathy (DR) remains the leading cause of blindness among working-age individuals in developed countries [4]. Whereas proliferarive diabetic retinopathy (PDR) is the commonest sight-threatening lesion in type 1 diabetes, diabetic macular edema (DME) is the primary cause of poor visual acuity in type 2 diabetes. Because of the high prevalence of type 2 diabetes, DME is the main cause of visual impairment in diabetic patients [5]. In addition, DME is almost invariably present when PDR is detected in type 2 diabetic patients [6]. Neovascularization due to severe hypoxia is the hallmark of PDR whereas vascular leakage due to the breakdown of the blood retinal barrier (BRB) is the main event involved in the pathogenesis of DME $[7,8]$. Most of the research on the physiopathology of DR has been focused in the impairment of the neuroretina and the breakdown of the inner BRB. By contrast, the effects of diabetes on the RPE have received less attention.

In the following sections the functions of the RPE mentioned above will be described in more detail, and the deleterious effects of diabetes will be summarized. Although there is growing evidence pointing to RPE as an active secretor epithelium, it seems that this important function has been less recognized. For this reason, this review will focus on this essential propriety of RPE and its impairment in DR.

\section{Transepithelial Transport}

In one direction, the RPE transports electrolytes and water from the subretinal space to the choroid, and in the other direction, the RPE transports glucose and other nutrients from the blood to the photoreceptors.

2.1. Transport from Blood to Photoreceptors. The RPE takes up nutrients such as glucose, retinol, ascorbic acid, and fatty acids from the blood and delivers these nutrients to the photoreceptors.

To transport glucose, the RPE contains high amounts of glucose transporters in both the apical and the basolateral membranes. Both GLUT1 and GLUT3 are highly expressed in the RPE [9-11]. GLUT3 mediates the basic glucose transport while GLUT1 is responsible for inducible glucose transport in response to different metabolic demands.

Another important function of the RPE is the transport of retinol to ensure the supply of retinal to the photoreceptors. The bulk of the retinal is exchanged between the RPE and the photoreceptors during the visual cycle in which alltrans-retinol is taken up from the photoreceptors, isomerized to 11-cis-retinal, and redelivered to photoreceptors [12].

Delivery of fatty acids such as docosahexaenoic acid (DHA) to the photoreceptors is a third kind of transport of importance for visual function [13]. DHA is an essential omega-3 fatty acid that cannot be synthesized by neural tissue but is required as structural element by membranes of neurons and photoreceptors. DHA is synthesized from its precursor, linolenic acid, in the liver and transported in the blood bound to plasma lipoprotein where it is taken up in a concentration-dependent manner [1, 14]. Apart from the RPE's functional integrity, DHA is the precursor of neuroprotectin D1 (NPD1), a docosatriene that protects RPE cells from oxidative stress $[15,16]$.

Recently it has been demonstrated that high glucose downregulates GLUT-1 by Akt pathway activation mediated by the PKC-oxidative stress signaling pathway in ARPE cells (a spontaneously immortalized line of RPE cells) [17]. In addition, the transport of retinol may be altered due to a downregulation of the interstitial retinol binding protein (IRBP) that occurs in diabetic patients (see below). Finally an impairment of the transport of ascorbic acid also exists in the presence of hyperglycemia, thus limiting the RPE's antioxidant defence $[18,19]$. To the best of our knowledge, there is no information regarding the potential effects of diabetes on NPD1 or its precursor DHA.

\subsection{Transport from Subretinal Space to Blood. The RPE} transports ions and water from the subretinal space or apical side to the blood or basolateral side [1]. The $\mathrm{Na}^{+}-\mathrm{K}^{+}$-ATPase, which is located in the apical membrane, provides the energy for transepithelial transport [20-23].

There is a large amount of water produced in the retina, mainly as a consequence of the large metabolic turnover in neurons and photoreceptors. Furthermore, intraocular pressure leads to a movement of water from the vitreous body into the retina. This establishes the need for the constant removal of water from the inner retina to the choriocapillaris [24]. Water in the inner retina is transported by Müller cells, and water in the subretinal space is eliminated by the RPE $[25,26]$. Constant elimination of water from the subretinal space produces an adhesion force between the retina and the RPE that is lost by inhibition of $\mathrm{Na}^{+}-\mathrm{K}^{+}$-ATPase by ouabain [27]. The transport of water is mainly driven by a transport of $\mathrm{Cl}^{-}$and $\mathrm{K}^{+}[24,28-30]$.

Tight junctions establish a barrier between the subretinal space and the choriocapillaris [31, 32]. Paracellular resistance is 10 times higher than transcellular resistance, classifying the RPE as a tight epithelium [33, 34]. For this reason, water cannot pass through the paracellular transport route and water transport occurs mainly by transcellular pathways facilitated by aquaporin-1 [35-37].

Recently we have found that high glucose concentrations result in a reduction of permeability in ARPE-19 cells [38] that was unrelated to tight junction (occludin, ZO-1 and claudin-1) changes. In this regard, in cultured bovine RPE cells it has been demonstrated that hyperglycemia induces a loss of $\mathrm{Na}+/ \mathrm{K}(+)$-ATPase function, which responds to aldose reductase inhibitor treatment [39]. Therefore, hyperglycemia could impair the transport of water from subretinal space to the choriochapilaris and, consequently, might contribute to DME development.

At present, there is no information regarding the potential effects of diabetes on aquaporin expression in the RPE.

\section{Absorption of Light and Protection against Photooxidation}

The retina is the only neural tissue that has a direct and frequent exposure to light. This circumstance favours the 


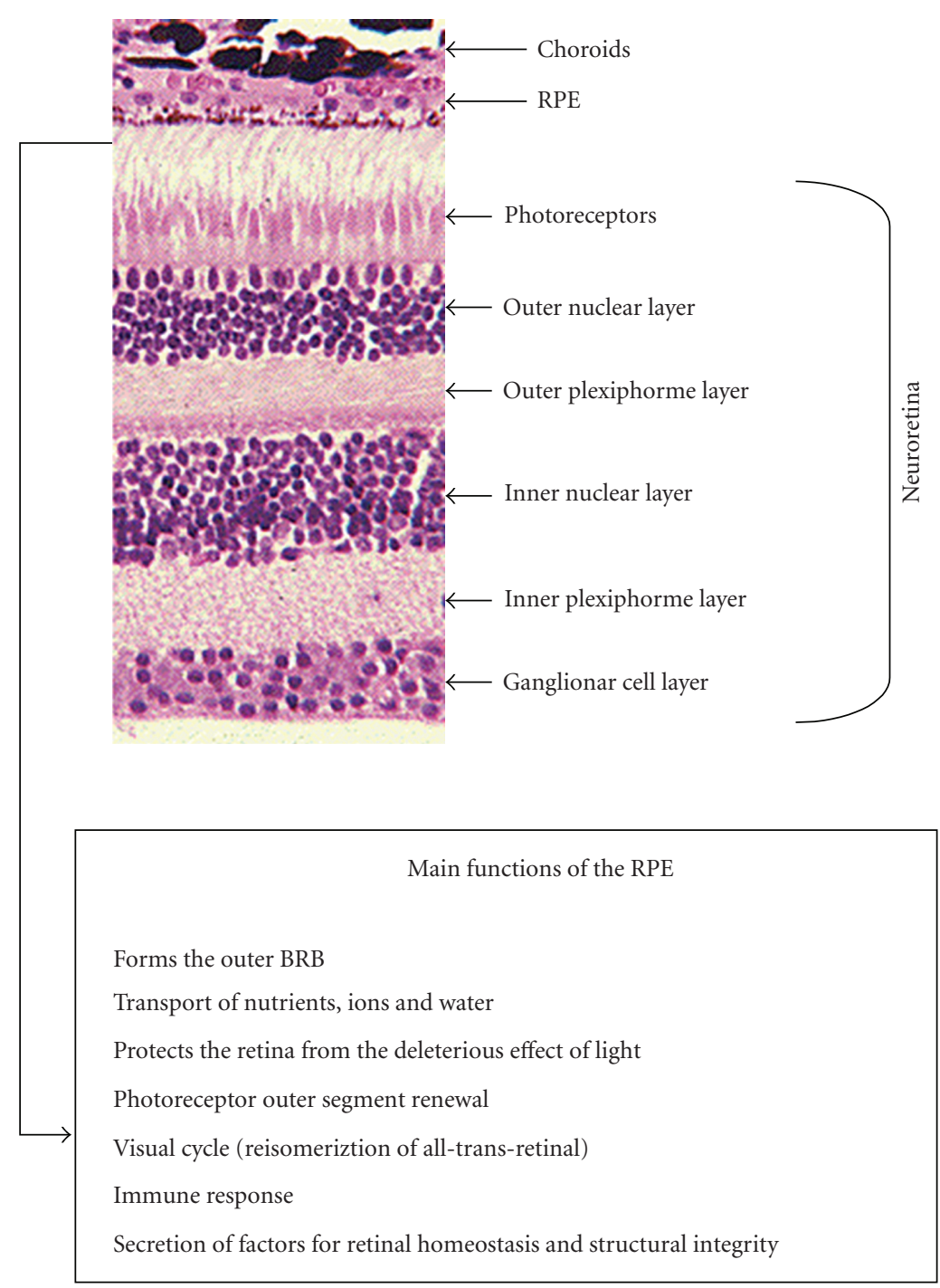

FIGURE 1: Retinal section of the retina showing the location of the retinal pigment epithelium (RPE). In the box are listed the main functions of RPE.

photooxidation of lipids which become extremely toxic to retinal cells [40]. In addition, the retina is the part of the body that proportionally consumes more oxygen, thus generating a high rate of reactive oxygen species (ROS). The RPE is essential in counterbalancing the high oxidative stress that exists in the retina, and it does this by means of three lines of defence.

The first line is the absorption and filtering of light. For this purpose, the RPE contains a complex composition of various pigments (i.e., melanin, lipofucsin) that are specialized to different wavelengths and special wavelengthdependent risks [41-43]. The second line of defence is made by antioxidants. As enzymatic antioxidants, the RPE contains high amounts of superoxide dismutase [44-47] and catalase $[45,48]$. As nonenzymatic antioxidants, the RPE accumulates carotenoids, such as lutein and zeaxanthin $[42,43]$ or ascorbate $[42,49]$. In addition, glutathione and melanin are important contributors to antioxidant defence.
DR is characterized by reduced levels of molecules with antioxidant activity such as glutathione [50,51], superoxide dismutase (SOD) [50, 52], and ascorbic acid [18, 53], thus favouring retinal tissue damage induced by oxidative stress.

\section{Visual Cycle}

In vertebrate retina, vision is initiated and maintained by the photolysis and regeneration, respectively, of light sensitive pigments in the disk membranes of the photoreceptor outer segments. This cyclical process depends on an exchange of retinoids between the photoreceptors and the RPE.

Light transduction is initiated by the absorption of light by rhodopsin which is composed of a seven transmembrane domain G-coupled receptor protein, opsin, and the chromophore 11-cis-retinal [54]. Absorption of light changes the conformation of 11-cis-retinal into all-transretinal. Photoreceptors lack cis-trans isomerase and, therefore, all-transretinal is metabolized into all-trans-retinol and transported 


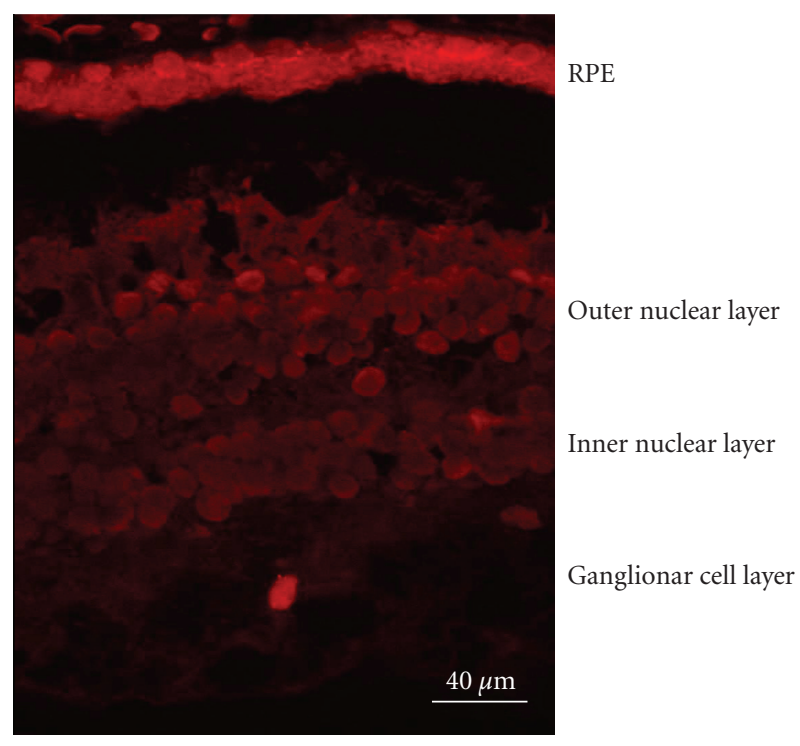

FIgURE 2: Confocal microscopy showing the expression of somatostatin (SST) in the human retina. As can be appreciated SST expression (in red) is higher in the RPE than in the neuroretina.

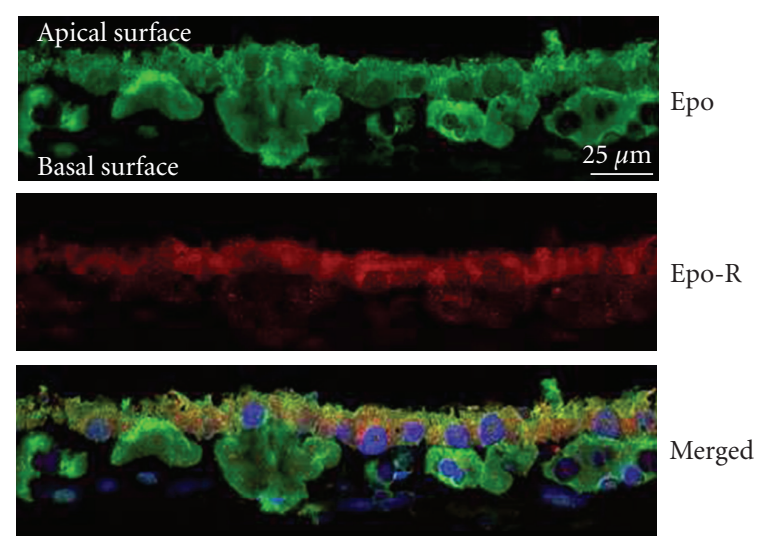

FIgURE 3: Confocal microscopy of human RPE showing the expression of both erythropoietin (Epo) in green and Epo receptor (Epo-R) in red. At the bottom the merged image shows partial colocalization of Epo and Epo-R.

to the RPE. In the RPE retinol is reisomerized by means of cis-trans isomerase to 11-cis-retinal and then redelivered to the photoreceptors. The protein RPE65 (retinal pigment epithelium-specific protein $65 \mathrm{kDa}$ ) is the protein responsible for isomerization of the all-trans-retinaldehyde to its photoactive 11-cis-retinaldehyde and is essential for the visual cycle. In this regard, it has been shown that RPE65 mutations cause severe retinal diseases such as Leber congenital amaurosis [55].

There is a great deal of evidence that the transport of retinoids between these cellular compartments is mediated by the interphotoreceptor retinoid-binding protein (IRBP), a large glycoprotein synthesized in the photoreceptors and extruded into the interphotoreceptor matrix (IPM) that fills the subretinal space [56-58]. IRBP functions to solubilize

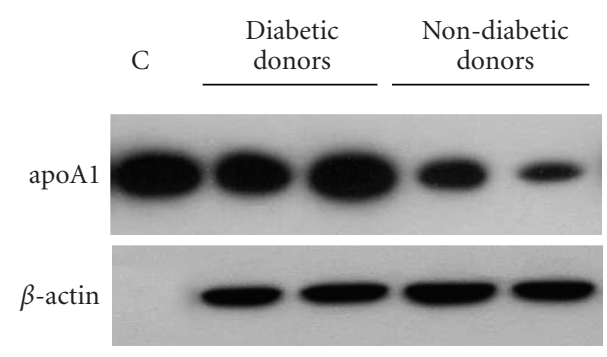

(a)

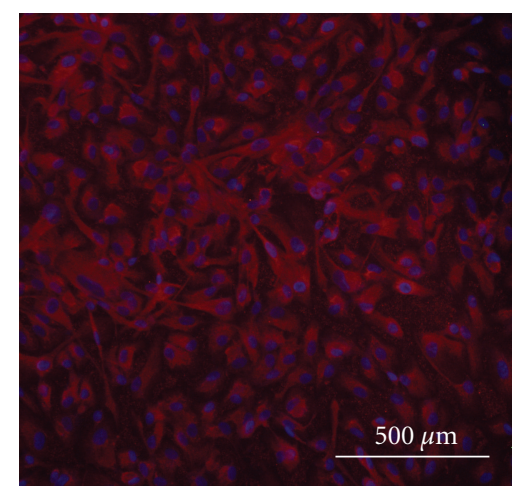

(b)

FIgURE 4: (a) Immunoblot showing higher protein content of apolipoprotein A1 (apoA1) in RPEs from diabetic donors in comparison with RPEs from nondiabetic donors. (b) Inmmunofluorescent image of apoA1 (red) in ARPE cells (spontaneously immortalized cell line of human RPE).

retinal and retinol, which are otherwise insoluble in water, and mediates the targeting of these compounds and defines transport direction [59-62]. This role for IRBP is further supported by the observation that IRBP is not only present in the IPM but also in endosomes of the RPE [63]. Transport direction is then defined by the rapid turnover of IRBP between the IPM and the RPE. Apart from participating in the visual cycle, IRBP is important in fatty acid transport and is essential to the maintenance of the photoreceptors $[58,64]$.

Recently, it has been demonstrated that lower IRBP production is an early event in the human diabetic retina and is associated with retinal neurodegeneration $[65,66]$. In addition, the content of cellular retinaldehyde binding protein (CRALBP), a protein also related to retinoid metabolism, has been found increased in RPE from diabetic subjects with no clinically apparent diabetic retinopathy in comparison with control donors [67].

\section{Phagocytosis}

Another function in the maintenance of photoreceptor excitability is the phagocytosis of shed photoreceptor outer segments [68-70]. Photoreceptors are exposed to intense levels of light, thus leading to accumulation of photodamaged proteins and lipids. Thus, during each day, the concentration of light-induced toxic substances increases 
inside the photoreceptors [42]. Light transduction by photoreceptors is dependent on the proper functioning and structure of proteins, retinal, and membranes. Therefore, to maintain the excitability of photoreceptors, the photoreceptor outer segments (POSs) undergo a constant renewal process $[69,71,72]$. In this renewal process POSs are newly built from the base of outer segments, at the cilium. The tips of the POS that contain the highest concentration of radicals, photodamaged proteins, and lipids are shed from the photoreceptors. Through coordinated POSs tip shedding and the formation of new POS, a constant length of the POS is maintained. Shed POSs are phagocytosed by the RPE. In the RPE, shed POS are digested and essential molecules, such as docosahexaenoic acid and retinal, are redelivered to photoreceptors to rebuild light-sensitive outer segments from the base of the photoreceptors $[69,73]$.

An impairment of phagocytosis has been described in long term diabetes [74] and, therefore, it is possible that this could also happen to RPE cells. However, specific studies addressed to this issue are needed.

\section{Secretion}

The RPE is known to produce and to secrete a variety of growth factors $[7,75]$ as well as factors that are essential for the maintenance of the structural integrity of the retina $[76,77]$ and choriocapillaris [78]. Thus, the RPE produces molecules that support the survival of photoreceptors and ensure a structural basis for the optimal circulation and supply of nutrients. The RPE is able to secrete pigment epithelium-derived factor (PEDF) [7, 79, 80], VEGF [7, 8185], fibroblast growth factors (FGF-1, FGF-2, and FGF-5) $[7,86-91]$, transforming growth factor- $\beta$ (TGF- $\beta)[7,92-$ 94], insulin-like growth factor-I (IGF-I) [95, 96], nerve growth factor (NGF), brain-derived growth factor (BDNF), neurotropin-3 (NT-3), ciliary neurotrophic factor (CNTF) [97, 98], platelet-derived growth factor (PDGF) [7, 99, 100], lens epithelium-derived growth factor (LEDGF) [101], members of the interleukin family [102-104], chemokines, tumor necrosis factor $\alpha$ (TNF- $\alpha$ ), colony-stimulating factors (CSF), and different types of tissue inhibitor of matrix metalloprotease (TIMP) [105-110]. Among these factors, PEDF and VEGF seem the most significant.

6.1. PEDF and VEGF. In the healthy eye, the RPE secretes PEDF $[7,80-82]$, which helps to maintain the retinal as well as the choriocapillaris structure in two ways. PEDF was described as a neuroprotective factor because it was shown to protect neurons against glutamate-induced or hypoxia-induced apoptosis $[76,111,112]$. In addition, PEDF was shown to function as an antiangiogenic factor that inhibited endothelial cell proliferation and stabilized the endothelium of the choriocapillaris [7, 81, 82]. These effects on vascularization also play an important role in the embryonic development of the eye [113, 114]. Using PEDF-deficient (PEDF-/-) mice, it has been confirmed that PEDF is an important modulator of early postnatal retinal vascularization and that in its absence retinal vascularization proceeds at a faster rate and is more susceptible to hyperoxiamediated vessel obliteration [115].

Another vasoactive factor synthesized by the RPE is VEGF, which is secreted in low concentrations by the RPE in the healthy eye $[7,83,86]$ where it prevents endothelial cell apoptosis and is essential for an intact endothelium of the choriocapillaris [116]. VEGF also acts as a permeability factor stabilizing the fenestrations of the endothelium [117]. In a healthy eye, PEDF and VEGF are secreted at opposite sides of the RPE. PEDF is secreted to the apical side where it acts on neurons and photoreceptors whereas most of VEGF is secreted to the basal side where it acts on the choroidal endothelium $[118,119]$.

Overproduction of VEGF plays an essential role in the development of PDR. The pathogenesis of DME remains to be fully understood but VEGF and proinflammatory cytokines have been involved in its development. Nevertheless, the balance between angiogenic (i.e., VEGF) and antiangiogenic factors (i.e., PEDF) will be crucial for the development of DR. In this regard, advanced glycation end products increase retinal VEGF expression in RPE [120]. Downregulation of PEDF expression by elevated glucose concentration in cultured human RPE cells was also observed [121]. Therefore, strategies in blocking VEGF or stimulating PEDF have been proposed as new therapeutic approaches for DR.

Apart from the factors mentioned above, in recent years new molecules have been found to be synthesized in RPE. Among them, somatostatin, erythropoietin, and ApoA1 seem to be of special interest because they could open up new therapeutic strategies for the treatment of DR.

6.2. Somatostatin. Somatostatin (SST) is a peptide that was originally identified as the hypothalamic factor responsible for inhibition of the release of growth hormone $(\mathrm{GH})$ from the anterior pituitary [122]. Subsequent studies have shown that SST has a much broader spectrum of inhibitory actions and that it is much more widely distributed in the body, occurring not only in many regions of the central nervous system but also in many tissues of the digestive tract, including the stomach, intestine, and pancreas [123]. SST mediates its multiple biologic effects via specific plasma membrane receptors that belong to the family of G-proteincoupled receptors having seven transmembrane domains. So far, five SST receptor subtypes (SSTRs) have been identified (SSTRs 1-5) [124].

In the setting of this review it must be pointed out that SST is produced by the retina of various species, including humans [125-130]. Furthermore, SSTRs are also expressed in the retina, with SSTR1 and SSTR2 being the most widely expressed [127, 131-134]. The production of both SST and its receptors simultaneously suggests an autocrine action in the human retina.

The amount of SST produced by the retina is significant as can be deduced by the strikingly high levels found in the vitreous fluid. In fact, intravitreal levels of SST are higher than in plasma. It must be emphasized that the intravitreous level of total proteins is at least 20-fold less 
than in serum $[135,136]$. Thus, the higher intravitreal concentration of a particular protein in relation to its plasma levels strongly suggests an important rate of intraocular production. The main source of SST in humans is RPE. Thus, it has been demonstrated that SST expression and content is higher in RPE than in the neuroretina (Figure 2) [137].

The main functions of SST for retinal homeostasis are the following (1) SST acts as a neuromodulator through multiple pathways, including intracellular $\mathrm{Ca}^{2+}$ signaling [138], nitric oxide function [139], and glutamate release from the photoreceptors [140]. In addition, a loss in SST immunoreactivity was found after degeneration of the ganglion cells [141]. It should be noted that retinal ganglion cells (RGCs) are the earliest cells affected and have the highest rate of apoptosis in diabetes [137, 142]. This could be because RGCs are more sensitive to hypoxic conditions and glutamate excitotoxicity [143]. Therefore, the neuroretinal damage that occurs in DR might be the reason for the decreased SST levels detected in the vitreous fluid of these patients. In fact we have recently found that low SST expression and production is an early event in DR and is associated with retinal neurodegeneration (apoptosis and glial activation) [137]. (2) SST is an angiostatic factor. SST may reduce endothelial cell proliferation and neovascularisation by multiple mechanisms, including the inhibition of postreceptor signalling events of peptide growth factors such as IGF-I, VEGF, epidermal growth factor (EGF), and PDGF [144]. Using a mouse model of hypoxia-induced retinopathy, it has been demonstrated that in retinas overexpressing subtype 2 receptor of somatostatin (sst2) neovascularization was lower than in wild type retinas [145]. In addition, also using a mouse model of hypoxia-induced retinopathy it has been observed that retinal neovascularization increased in sst(2)-KO mice [146]. Furthermore, both SSTR2- and SSTR3- selective analogues directly inhibit retinal endothelial cell growth in vitro [147, 148]. It is worthy of mention that the intravitreal levels of SST lie within the same range as those showing antiangiogenic effect in experimental studies [149-151]. Therefore, SST can be considered as a good candidate to be added to the list of the natural inhibitors of angiogenesis. (3) SST has been involved in the transport of water and ions. As previously mentioned, various ion/water transport systems are located on the apical side of the RPE, adjacent to the subretinal space, and, indeed, a high expression of SST-R2 has been shown in this apical membrane of the RPE [131]. Nevertheless, the specific mechanisms involved in ion/water transport driven by SST remain to be elucidated.

In DR there is a downregulation of SST that is associated with retinal neurodegeneration [137]. Thus, a lower expression of SST has been found in RPE and neuroretina as well as a dramatic decrease of intavitreal SST levels [137, 152154]. As a result, the physiological role of SST in preventing both neovascularisation and fluid accumulation within the retina is reduced, and consequently the development of PDR and DME is favoured [153, 154]. In addition, the loss of neuromodulator activity also contributes to neuroretinal damage. For all these reasons, intravitreal injection of SST analogues or gene therapy has been proposed as a new therapeutic approach in DR [155].

6.3. Erythropoietin. Erythropoietin (Epo) was first described as a glycoprotein produced exclusively in fetal liver and adult kidney that acts as a major regulator of erythropoiesis [156]. However, Epo expression has also been found in the human brain [157] and in the human fetal retina [158]. In recent years, we have demonstated that not only Epo but also its receptor (Epo-R) is expressed in the adult human retina (Figure 3) [159, 160]. Epo and EpoR mRNAs are significantly higher in RPE than in the neuroretina [160].

In addition, intravitreal levels of Epo are $\sim 3.5$-fold higher than those found in plasma [159]. The role of Epo in the retina remains to be elucidated but it seems that it has a potent neuroprotective effect $[161,162]$. In this regard, it has been shown that Epo protects cultured neurons from hypoxia and glutamate toxicity [163-165], and its systemic administration reduces neuronal injury in animal models of focal ischemic stroke and inflammation [166-168]. In addition, it has been demonstrated using an in vitro model of bovine blood-brain barrier (BBB) that Epo protects against the VEGF-induced permeability of the BBB and restores the tight junction proteins [169]. Since BRB is structurally and functionally similar to the $\mathrm{BBB}[170]$, it is possible that Epo could act as an antipermeability factor in the retina. In fact, Epo was able to improve DME when administered for treatment of anemia in diabetic patients with renal failure [171].

Epo is upregulated in DR $[159,160,172,173]$. Epo overexpression has been found in both the RPE and neuroretina of diabetic eyes $[159,160]$. This is in agreement with the elevated concentrations of Epo found in the vitreous fluid of diabetic patients ( $\sim 30$-fold higher than plasma and $\sim 10$-fold higher than in non diabetic subjects) [159]. Hypoxia is a major stimulus for both systemic [156] and intraocular Epo production [174]. In fact, high intravitreous levels of Epo have recently been reported in ischemic retinal diseases such as PDR $[159,172,173,175]$. In addition, it has been reported that Epo has an angiogenic potential equivalent to VEGF $[173,176]$. Therefore, Epo could be an important factor involved in stimulating retinal angiogenesis in PDR. However, intravitreal levels of Epo have been found at a similar range in PDR to that in DME (a condition in which hypoxia is not a predominant event) [159]. In addition, intravitreal Epo levels are not elevated in non diabetic patients with macular edema secondary to retinal vein occlusion [177]. Finally, a higher expression of Epo has been detected in the retinas from diabetic donors at early stages of DR in comparison with non diabetic donors, and this overexpression is unrelated to mRNA expression of hypoxic inducible factors (HIF-1 $\alpha$ and HIF-1 $\beta$ ) [160]. Therefore, stimulating agents other than hypoxia/ischemia are involved in the upregulation of Epo that exists in the diabetic eye.

The reason why Epo is increased in DR remains to be elucidated but the bulk of the available information points to a protective effect rather than a pathogenic effect, at least in the early stages of DR. There have been several 
reports on the protective effects of Epo in the retina $[175,178-185]$. In addition, Epo is a potent physiologic stimulus for the mobilization of endothelial progenitor cells (EPCs) [186] and, therefore, it could play a relevant role in regulating the traffic of circulating EPCs towards injured retinal sites. Recruitment of EPCs to the pathologic area would be beneficial because their capability of integrating into damaged vasculature can lead to the reendothelization of acellular vessels. It has recently been shown that a reduction of EPCs exists in nonproliferarive DR [187] and it has also been demonstrated that EPCs from diabetic donors are less effective in repairing damaged vasculature [188]. In this regard, the increase of intraocular synthesis of Epo that occurs in early stages of DR (i.e., in nonproliferative DR) can be contemplated as a compensatory mechanism for repairing the damage induced by the diabetic milieu through an increase in EPC recruitment. However, in advanced stages of DR (i.e., in the setting of PDR) a dramatic increase of both VEGF [7] and mature EPCs has been detected [187]. In this setting, Epo could potentiate the effects of VEGF, thus contributing to neovascularisation and, in consequence, worsening PDR [181, 189].

The potential advantages of Epo or EpoR agonists in the treatment of DR include neuroprotection, vessel stability, and enhanced recruitment of EPCs to the pathological area. However, as mentioned above, timing is critical since if Epo is given at later hypoxic stages, the severity of DR could even increase. However, in the case of the eye, disease progression is easy to follow without invasive investigation and allows timing of the administration of drugs to be carefully monitored, hopefully resulting in better clinical outcomes.

6.4. Apolipoprotein A1. Apolipoprotein A1 (apoA1) has been recently proposed as a key factor for intraretinal reverse transport of lipids, thus preventing lipid accumulation in the retina [190]. In a proteomic analysis of human vitreous fluid we found that apoA1 was highly intraocularly produced in patients with proliferative DR in comparison with nondiabetic subjects [65]. In addition, we have recently shown higher apoA1 (both mRNA levels and protein) in the retinas from diabetic donors in comparison with non-diabetic donors (Figure 4) [191, 192]. Moreover, apoA1 immunofluorescence was detected in all retinal layers but mRNA was more abundant in RPE [55]. This finding suggests that RPE is the main source of apoA1 in the human retina. These results are consistent with those reported by Li et al. [193] which demonstrated the immunolocalization of apoA1 to Bruch's membrane (a thin connective tissue between the basal surface of the RPE and the choriocapillaris) in postmortem human eye specimens as well as the presence of apoA1 transcripts in the RPE and neural retina. Several independent lines of research indicate that the RPE contains LDL receptors (LDLRs) and/or scavenger receptors by which lipoproteins (LDL) are internalized and serve as a significant supply of lipids to the retina [194-196]. Taken together, the RPE, due to its capacity in internalizing and extruding lipids, can be considered as the most important regulator of lipid transport in the retina.
The reason why apoA1 is overexpressed in the diabetic retina needs to be elucidated but one possibility is that the diabetic milieu stimulates apoA1 production by the retina. In this regard, Kawai et al. [197] observed an increased secretion of apoA1 from the main lacrimal gland in patients with DR, but it was not detected in healthy subjects. In recent years new insights have been gained into the transport of lipids within the retina $[190,194]$, thus allowing us to hypothesize that the mechanisms regulating intraretinal lipid transport rather than serum levels are more important in the pathogenesis of DR [191, 192, 198]. In this regard, ABCA (ATP binding cassette transporter A1) and apoA1 have been found in several layers of monkey retina, thus suggesting the existence of an intraretinal mechanism to export HDL-like particles [190]. Ishida et al. [199] have demonstrated that HDL stimulates the efflux of radiolabelled lipids, of photoreceptor outer segment origin, from the basal surface of RPE cells in culture. The role of this HDLbased intraretinal lipid transport could be important in preventing lipotoxicity. The fact that the retina is the only neural tissue that has a direct and frequent exposure to light presents a significant problem. This is because many lipids, especially polyunsaturated fatty acids (which are mainly located in the photoreceptor outer segments) and cholesterol esters, are highly susceptible to photo-oxidation and these oxidized lipids become extremely toxic to retinal cells [40]. In DR, this problem could be aggravated by the increase of oxidative stress and lipid peroxidation associated with diabetes. Apart from preventing or arresting lipotoxicity, apoA1 is a potent scavenger of reactive oxygen species [200, 201]; therefore, it could play an important role in protecting the retina from the overall oxidative stress due to diabetes. In this regard, it should be noted that retinopathy has been associated with apoA1 deficiency of genetic origin [202, 203].

Lipoprotein deposition plays an essential role in the pathogenesis of age-related macular degeneration (ARMD) [204, 205], but little is known about the origin of lipoproteins in the retina of diabetic patients and their potential role in the pathogenesis of DR. The role of apoA1 in extruding lipids out of the retina permits us to hypothesize that apoA1 is increased in diabetic patients as a compensatory mechanism in order to prevent the development of DR [67]. In other words, those diabetic patients with less capacity for apoA 1 production by the retina would be more prone to develop lipid deposition (hard exudates) in the retina and, in consequence, to initiate DR.

Given that apoA1 has antioxidant properties and prevents lipid deposition in the retina, the design of new treatment strategies addressed to promoting the overexpression of apoA1 in order to reduce the development of DR seems warranted.

\section{Concluding Remarks}

The RPE lies in the interface between the neural retina and the choriocapillaris where it forms the outer BRB. To retard transepithelium diffusion between cells, the cells of the epithelium are bound together by a partially occluding 
seal, the tight junction. The tight junction subdivides the plasma membrane into two functionally distinct domains. The apical membrane faces the photoreceptors of the neural retina, while the basolateral membrane faces the fenestrated choriochapillaris.

As a layer of pigmented cells the RPE absorbs the light energy focused by the lens on the retina. To regulate transport across the monolayer, various pumps, channels, and transporters are distributed specifically to either the apical or the basolateral membrane. The RPE transports ions, water, and metabolic end products from the subretinal space to the blood and, conversely, takes up nutrients such as glucose, retinol, and fatty acids from the blood and delivers these nutrients to the photoreceptors. To maintain photoreceptor excitability retinal is constantly transported from the photoreceptors to the RPE where it is reisomerized to 11-cisretinal and transported back to the photoreceptors. This is the key component of the visual cycle. Another function that contributes to the maintenance of photoreceptor excitability is the phagocytosis of the shed photoreceptor outer segments. The photoreceptor outer segments are digested, and essential substances such as retinal are recycled and returned to the photoreceptors for rebuilding light-sensitive outer segments from the base of the photoreceptors. In addition, the RPE is able to secrete a variety of growth factors as well as factors that are essential for the maintenance of the structural integrity of the retina and the choriocapillaris. Furthermore, the secretory activity of the RPE plays an important role in establishing the immune privilege of the eye by secreting immunosuppressive factors.

Most investigations into the pathogenesis of DR have been concentrated on the neural retina since this is where clinical lesions are manifested. However, RPE is essential for neuroretina survival and, consequently, for visual function. In recent years, various abnormalities in both the structural and secretory functions of RPE have been found in DR. Therefore, future scenarios involving new therapeutic strategies addressed to modulating RPE impairment are warranted.

\section{Acknowledgments}

This study was supported by grants from the Generalitat de Catalunya (2009SGR739) and the Ministerio de Ciencia e Innovación (SAF2006-05284). CIBER de Diabetes y Enfermedades Metabólicas Asociadas is an initiative of the Instituto de Salud Carlos III. Marta Villaroel is a recipient of a grant from the Institut de Recerca Hospital Vall d'Hebron.

\section{References}

[1] O. Strauss, "The retinal pigment epithelium in visual function," Physiological Reviews, vol. 85, no. 3, pp. 845-881, 2005.

[2] R. H. Steinberg, "Interactions between the retinal pigment epithelium and the neural retina," Documenta Ophthalmologica, vol. 60, no. 4, pp. 327-346, 1985.

[3] G. M. Holtkamp, A. Kijlstra, R. Peek, and A. F. de Vos, "Retinal pigment epithelium-immune system interactions: cytokine production and cytokine-induced changes,"
Progress in Retinal and Eye Research, vol. 20, no. 1, pp. 29-48, 2001.

[4] N. G. Congdon, D. S. Friedman, and T. Lietman, "Important causes of visual impairment in the world today," Journal of the American Medical Association, vol. 290, no. 15, pp. 20572060, 2003.

[5] S. Lightman and H. M. A. Towler, "Diabetic retinopathy," Clinical Cornerstone, vol. 5, no. 2, pp. 12-21, 2003.

[6] L. Tong, S. A. Vernon, W. Kiel, V. Sung, and G. M. Orr, "Association of macular involvement with proliferative retinopathy in type 2 diabetes," Diabetic Medicine, vol. 18, no. 5, pp. 388-394, 2001.

[7] R. Simó, E. Carrasco, M. García-Ramírez, and C. Hernández, "Angiogenic and antiangiogenic factors in proliferative diabetic retinopathy," Current Diabetes Reviews, vol. 2, no. 1, pp. 71-98, 2006.

[8] A. Joussen, N. Smyth, and C. Niessen, "Pathophysiology of diabetic macular edema," Developments in Ophthalmology, vol. 39, pp. 1-12, 2007.

[9] Y. Ban and L. J. Rizzolo, "Regulation of glucose transporters during development of the retinal pigment epithelium," Developmental Brain Research, vol. 121, no. 1, pp. 89-95, 2000.

[10] L. Bergersen, E. Jóhannsson, M. L. Veruki, et al., "Cellular and subcellular expression of monocarboxylate transporters in the pigment epithelium and retina of the rat," Neuroscience, vol. 90, no. 1, pp. 319-331, 1999.

[11] P. deS Senanayake, A. Calabro, J. G. Hu, et al., "Glucose utilization by the retinal pigment epithelium: evidence for rapid uptake and storage in glycogen, followed by glycogen utilization," Experimental Eye Research, vol. 83, no. 2, pp. 235-246, 2006.

[12] W. Baehr, S. M. Wu, A. C. Bird, and K. Palczewski, "The retinoid cycle and retina disease," Vision Research, vol. 43, no. 28, pp. 2957-2958, 2003.

[13] N. G. Bazan, W. C. Gordon, and E. B. Rodriguez de Turco, "Docosahexaenoic acid uptake and metabolism in photoreceptors: retinal conservation by an efficient retinal pigment epithelial cell-mediated recycling process," Advances in Experimental Medicine and Biology, vol. 318, pp. 295-306, 1992.

[14] R. E. Anderson, P. J. O’Brien, R. D. Wiegand, C. A. Koutz, and A. M. Stinson, "Conservation of docosahexaenoic acid in the retina," Advances in Experimental Medicine and Biology, vol. 318, pp. 285-294, 1992.

[15] P. K. Mukherjee, V. L. Marcheselli, C. N. Serhan, and N. G. Bazan, "Neuroprotectin D1: a docosahexaenoic acid-derived docosatriene protects human retinal pigment epithelial cells from oxidative stress," Proceedings of the National Academy of Sciences of the United States of America, vol. 101, no. 22, pp. 8491-8496, 2004.

[16] N. G. Bazan, "Neurotrophins induce neuroprotective signaling in the retinal pigment epithelial cell by activating the synthesis of the anti-inflammatory and anti-apoptotic neuroprotectin d1," Advances in Experimental Medicine and Biology, vol. 613, pp. 39-44, 2008.

[17] D.-I. Kim, S.-K. Lim, M.-J. Park, H.-J. Han, G.-Y. Kim, and S. H. Park, "The involvement of phosphatidylinositol 3-kinase /Akt signaling in high glucose-induced downregulation of GLUT-1 expression in ARPE cells," Life Sciences, vol. 80, no. 7, pp. 626-632, 2007.

[18] R. Salceda and C. Contreras-Cubas, "Ascorbate uptake in normal and diabetic rat retina and retinal pigment 
epithelium," Comparative Biochemistry and Physiology C, vol. 146, no. 1-2, pp. 175-179, 2007.

[19] A. Minamizono, M. Tomi, and K.-I. Hosoya, "Inhibition of dehydroascorbic acid transport across the rat blood-retinal and -brain barriers in experimental diabetes," Biological and Pharmaceutical Bulletin, vol. 29, no. 10, pp. 2148-2150, 2006.

[20] A. D. Marmorstein, "The polarity of the retinal pigment epithelium," Traffic, vol. 2, no. 12, pp. 867-872, 2001.

[21] T. J. Ostwald and R. H. Steinberg, "Localization of frog retinal pigment epithelium $\mathrm{Na}^{+}-\mathrm{K}^{+}$ATPase," Experimental Eye Research, vol. 31, no. 3, pp. 351-360, 1980.

[22] L. J. Rizzolo, “The distribution of $\mathrm{Na}^{+}, \mathrm{K}^{+}$-ATPase in the retinal pigmented epithelium from chicken embryo is polarized in vivo but not in primary cell culture," Experimental Eye Research, vol. 51, no. 4, pp. 435-446, 1990.

[23] L. J. Rizzolo, "Polarization of the $\mathrm{Na}^{+}, \mathrm{K}^{+}$-ATpase in epithelia derived from the neuroepithelium," International Review of Cytology, vol. 185, pp. 195-235, 1999.

[24] S. Hamann, "Molecular mechanisms of water transport in the eye," International Review of Cytology, vol. 215, pp. 395431, 2002.

[25] H. Moseley, W. S. Foulds, D. Allan, and P. M. Kyle, "Routes of clearance of radioactive water from the rabbit vitreous," British Journal of Ophthalmology, vol. 68, no. 3, pp. 145-151, 1984.

[26] E. A. Nagelhus, Y. Horio, A. Inanobe, et al., "Immunogold evidence suggests that coupling of $\mathrm{K}^{+}$siphoning and water transport in rat retinal Muller cells is mediated by a coenrichment of Kir4.1 and AQP4 in specific membrane domains," GLIA, vol. 26, no. 1, pp. 47-54, 1999.

[27] D. A. Frambach, C. E. Roy, J. L. Valentine, and J. J. Weiter, "Precocious retinal adhesion is affected by furosemide and ouabain," Current Eye Research, vol. 8, no. 6, pp. 553-556, 1989.

[28] J. G. Hu, R. P. Gallemore, D. Bok, and D. A. Frambach, "Chloride transport in cultured fetal human retinal pigment epithelium," Experimental Eye Research, vol. 62, no. 4, pp. 443-448, 1996.

[29] M. F. Marmor, "Control of subretinal fluid: experimental and clinical studies," Eye, vol. 4, part 2, pp. 340-344, 1990.

[30] S. S. Miller and J. L. Edelman, "Active ion transport pathways in the bovine retinal pigment epithelium," Journal of Physiology, vol. 424, pp. 283-300, 1990.

[31] Y. Ban and L. J. Rizzolo, "Differential regulation of tight junction permeability during development of the retinal pigment epithelium," American Journal of Physiology, vol. 279, no. 3, pp. C744-C750, 2000.

[32] K. K. Erickson, J. M. Sundstrom, and D. A. Antonetti, "Vascular permeability in ocular disease and the role of tight junctions," Angiogenesis, vol. 10, no. 2, pp. 103-117, 2007.

[33] S. S. Miller and R. H. Steinberg, "Active transport of ions across frog retinal pigment epithelium," Experimental Eye Research, vol. 25, no. 3, pp. 235-248, 1977.

[34] S. S. Miller and R. H. Steinberg, "Passive ionic properties of frog retinal pigment epithelium," Journal of Membrane Biology, vol. 36, no. 4, pp. 337-372, 1977.

[35] S. Hamann, T. Zeuthen, M. La Cour, et al., "Aquaporins in complex tissues: distribution of aquaporins 1-5 in human and rat eye," American Journal of Physiology, vol. 274, no. 5, pp. C1332-C1345, 1998.

[36] W. D. Stamer, D. Bok, J. Hu, G. J. Jaffe, and B. S. McKay, "Aquaporin-1 channels in human retinal pigment epithelium: role in transepithelial water movement," Investigative
Ophthalmology and Visual Science, vol. 44, no. 6, pp. 28032808, 2003.

[37] A. S. Verkman, J. Ruiz-Ederra, and M. H. Levin, "Functions of aquaporins in the eye," Progress in Retinal and Eye Research, vol. 27, no. 4, pp. 420-433, 2008.

[38] M. Villarroel, M. García-Ramírez, L. Corraliza, C. Hernández, and R. Simó, "Effects of high glucose concentration on the barrier function and the expression of tight junction proteins in human retinal pigment epithelial cells," Experimental Eye Research, vol. 89, no. 6, pp. 913-920, 2009.

[39] J. Y. Crider, T. Yorio, N. A. Sharif, and B. W. Griffin, "The effects of elevated glucose on $\mathrm{Na}^{+} / \mathrm{K}^{+}$-ATPpase of cultured bovine retinal pigment epithelial cells measured by a new nonradioactive rubidium uptake assay," Journal of Ocular Pharmacology and Therapeutics, vol. 13, no. 4, pp. 337-352, 1997.

[40] A. W. Girotti and T. Kriska, "Role of lipid hydroperoxides in photo-oxidative stress signaling," Antioxidants and Redox Signaling, vol. 6, no. 2, pp. 301-310, 2004.

[41] S. Beatty, M. Boulton, D. Henson, H.-H. Koh, and I. J. Murray, "Macular pigment and age related macular degeneration," British Journal of Ophthalmology, vol. 83, no. 7, pp. 867-877, 1999.

[42] S. Beatty, H.-H. Koh, M. Phil, D. Henson, and M. Boulton, "The role of oxidative stress in the pathogenesis of age-related macular degeneration," Survey of Ophthalmology, vol. 45, no. 2, pp. 115-134, 2000.

[43] S. Beatty, I. J. Murray, D. B. Henson, D. Carden, H.H. Koh, and M. E. Boulton, "Macular pigment and risk for age-related macular degeneration in subjects from a northern European population," Investigative Ophthalmology and Visual Science, vol. 42, no. 2, pp. 439-446, 2001.

[44] R. N. Frank, R. H. Amin, and J. E. Puklin, "Antioxidant enzymes in the macular retinal pigment epithelium of eyes with neovascular age-related macular degeneration," American Journal of Ophthalmology, vol. 127, no. 6, pp. 694709, 1999.

[45] M. V. Miceli, M. R. Liles, and D. A. Newsome, "Evaluation of oxidative processes in human pigment epithelial cells associated with retinal outer segment phagocytosis," Experimental Cell Research, vol. 214, no. 1, pp. 242-249, 1994.

[46] D. A. Newsome, E. P. Dobard, M. R. Liles, and P. D. Oliver, "Human retinal pigment epithelium contains two distinct species of superoxide dismutase," Investigative Ophthalmology and Visual Science, vol. 31, no. 12, pp. 2508-2513, 1990.

[47] P. D. Oliver and D. A. Newsome, "Mitochondrial superoxide dismutase in mature and developing human retinal pigment epithelium," Investigative Ophthalmology and Visual Science, vol. 33, no. 6, pp. 1909-1918, 1992.

[48] D. J. Tate Jr., M. V. Miceli, and D. A. Newsome, "Phagocytosis and $\mathrm{H}_{2} \mathrm{O}_{2}$ induce catalase and metallothionein gene expression in human retinal pigment epithelial cells," Investigative Ophthalmology and Visual Science, vol. 36, no. 7, pp. 12711279, 1995.

[49] D. A. Newsome, M. V. Miceli, M. R. Liles, D. J. Tate Jr., and P. D. Oliver, "Antioxidants in the retinal pigment epithelium," Progress in Retinal and Eye Research, vol. 13, no. 1, pp. 101123, 1994.

[50] M. Kanwar, P.-S. Chan, T. S. Kern, and R. A. Kowluru, "Oxidative damage in the retinal mitochondria of diabetic mice: possible protection by superoxide dismutase," Investigative Ophthalmology and Visual Science, vol. 48, no. 8, pp. 3805-3811, 2007. 
[51] S. A. Madsen-Bouterse and R. A. Kowluru, "Oxidative stress and diabetic retinopathy: pathophysiological mechanisms and treatment perspectives," Reviews in Endocrine and Metabolic Disorders, vol. 9, no. 4, pp. 315-327, 2008.

[52] K. C. Silva, M. A. B. Rosales, S. K. Biswas, J. B. Lopes de Faria, and J. M. Lopes de Faria, "Diabetic retinal neurodegeneration is associated with mitochondrial oxidative stress and is improved by an angiotensin receptor blocker in a model combining hypertension and diabetes," Diabetes, vol. 58, no. 6, pp. 1382-1390, 2009.

[53] A. Minamizono, M. Tomi, and K.-I. Hosoya, "Inhibition of dehydroascorbic acid transport across the rat blood-retinal and -brain barriers in experimental diabetes," Biological and Pharmaceutical Bulletin, vol. 29, no. 10, pp. 2148-2150, 2006.

[54] P. A. Hargrave, "Rhodopsin structure, function, and topography: the Friedenwald lecture," Investigative Ophthalmology and Visual Science, vol. 42, no. 1, pp. 3-9, 2001.

[55] J.-J. Pang, B. Chang, A. Kumar, et al., "Gene therapy restores vision-dependent behavior as well as retinal structure and function in a mouse model of RPE65 leber congenital amaurosis," Molecular Therapy, vol. 13, no. 3, pp. 565-572, 2006.

[56] F. Gonzalez-Fernandez, "Interphotoreceptor retinoidbinding protein-an old gene for new eyes," Vision Research, vol. 43, no. 28, pp. 3021-3036, 2003.

[57] Q. Wu, L. R. Blakeley, M. C. Cornwall, R. K. Crouch, B. N. Wiggert, and Y. Koutalos, "Interphotoreceptor retinoidbinding protein is the physiologically relevant carrier that removes retinol from rod photoreceptor outer segments," Biochemistry, vol. 46, no. 29, pp. 8669-8679, 2007.

[58] F. Gonzalez-Fernandez and D. Ghosh, "Focus on molecules: interphotoreceptor retinoid-binding protein (IRBP)," Experimental Eye Research, vol. 86, no. 2, pp. 169-170, 2008.

[59] T.-I. L. Okajima, D. R. Pepperberg, H. Ripps, B. Wiggert, and G. J. Chader, "Interphotoreceptor retinoid-binding: role in delivery of retinol to the pigment epithelium," Experimental Eye Research, vol. 49, no. 4, pp. 629-644, 1989.

[60] T.-I. L. Okajima, D. R. Pepperberg, H. Ripps, B. Wiggert, and G. J. Chader, "Interphotoreceptor retinoid-binding protein promotes rhodopsin regeneration in toad photoreceptors," Proceedings of the National Academy of Sciences of the United States of America, vol. 87, no. 17, pp. 6907-6911, 1990.

[61] D. R. Pepperberg, T. L. Okajima, H. Ripps, G. J. Chader, and B. Wiggert, "Functional properties of interphotoreceptor retinoid-binding protein," Photochemistry and Photobiology, vol. 54, no. 6, pp. 1057-1060, 1991.

[62] D. R. Pepperberg, T.-I. L. Okajima, B. Wiggert, H. Ripps, R. K. Crouch, and G. J. Chader, "Interphotoreceptor retinoidbinding protein (IRBP) - molecular biology and physiological role in the visual cycle of rhodopsin," Molecular Neurobiology, vol. 7, no. 1, pp. 61-84, 1993.

[63] L. L. Cunningham and F. Gonzalez-Fernandez, "Internalization of interphotoreceptor retinoid-binding protein by the Xenopus retinal pigment epithelium," Journal of Comparative Neurology, vol. 466, no. 3, pp. 331-342, 2003.

[64] G. I. Liou, Y. Fei, N. S. Peachey, et al., "Early onset photoreceptor abnormalities induced by targeted disruption of the interphotoreceptor retinoid-binding protein gene," Journal of Neuroscience, vol. 18, no. 12, pp. 4511-4520, 1998.

[65] M. García-Ramírez, F. Canals, C. Hernández, et al., "Proteomic analysis of human vitreous fluid by fluorescencebased difference gel electrophoresis (DIGE): a new strategy for identifying potential candidates in the pathogenesis of proliferative diabetic retinopathy," Diabetologia, vol. 50, no. 6, pp. 1294-1303, 2007.

[66] M. Garcia-Ramírez, C. Hernández, M. Villarroel, et al., "Interphotoreceptor retinoid-binding protein (IRBP) is downregulated at early stages of diabetic retinopathy," Diabetologia, vol. 52, no. 12, pp. 2633-2641, 2009.

[67] A. Decanini, P. R. Karunadharma, C. L. Nordgaard, X. Feng, T. W. Olsen, and D. A. Ferrington, "Human retinal pigment epithelium proteome changes in early diabetes," Diabetologia, vol. 51, no. 6, pp. 1051-1061, 2008.

[68] E. Bosch, J. Horwitz, and D. Bok, "Phagocytosis of outer segments by retinal pigment epithelium: phagosome-lysosome interaction," Journal of Histochemistry and Cytochemistry, vol. 41, no. 2, pp. 253-263, 1993.

[69] D. Bok, "The retinal pigment epithelium: a versatile partner in vision," Journal of Cell Science, vol. 17, pp. 189-195, 1993.

[70] S. C. Finnemann, "Focal adhesion kinase signaling promotes phagocytosis of integrin-bound photoreceptors," The EMBO Journal, vol. 22, no. 16, pp. 4143-4154, 2003.

[71] R. H. Steinberg, "Interactions between the retinal pigment epithelium and the neural retina," Documenta Ophthalmologica, vol. 60, no. 4, pp. 327-346, 1985.

[72] J. Nguyen-Legros and D. Hicks, "Renewal of photoreceptor outer segments and their phagocytosis by the retinal pigment epithelium," International Review of Cytology, vol. 196, pp. 245-313, 2000.

[73] C. Bibb and R. W. Young, "Renewal of fatty acids in the membranes of visual cell outer segments," Journal of Cell Biology, vol. 61, no. 2, pp. 327-343, 1974.

[74] B.-F. Liu, S. Miyata, H. Kojima, et al., "Low phagocytic activity of resident peritoneal macrophages in diabetic mice: relevance to the formation of advanced glycation end products," Diabetes, vol. 48, no. 10, pp. 2074-2082, 1999.

[75] H. Tanihara, M. Inatani, and Y. Honda, "Growth factors and their receptors in the retina and pigment epithelium," Progress in Retinal and Eye Research, vol. 16, no. 2, pp. 271301, 1997.

[76] W. Cao, J. Tombran-Tink, W. Chen, D. Mrazek, R. Elias, and J. F. McGinnis, "Pigment epithelium-derived factor protects cultured retinal neurons against hydrogen peroxide-induced cell death," Journal of Neuroscience Research, vol. 57, no. 6, pp. 789-800, 1999.

[77] F. R. Steele, G. J. Chader, L. V. Johnson, and J. Tombran-Tink, "Pigment epithelium-derived factor: neurotrophic activity and identification as a member of the serine protease inhibitor gene family," Proceedings of the National Academy of Sciences of the United States of America, vol. 90, no. 4, pp. 1526-1530, 1993.

[78] A. N. Witmer, G. F. J. M. Vrensen, C. J. F. Van Noorden, and R. O. Schlingemann, "Vascular endothelial growth factors and angiogenesis in eye disease," Progress in Retinal and Eye Research, vol. 22, no. 1, pp. 1-29, 2003.

[79] D. W. Dawson, O. V. Volpert, P. Gillis, et al., "Pigment epithelium-derived factor: a potent inhibitor of angiogenesis," Science, vol. 285, no. 5425, pp. 245-248, 1999.

[80] G. L. King and K. Suzuma, "Pigment-epithelium-derived factor-a key coordinator of retinal neuronal and vascular functions," The New England Journal of Medicine, vol. 342, no. 5, pp. 349-351, 2000.

[81] A. P. Adamis, D. T. Shima, K.-T. Yeo, et al., "Synthesis and secretion of vascular permeability factor/vascular endothelial growth factor by human retinal pigment epithelial cells," Biochemical and Biophysical Research Communications, vol. 193, no. 2, pp. 631-638, 1993. 
[82] P. F. Lopez, B. D. Sippy, H. M. Lambert, A. B. Thach, and D. R. Hinton, "Transdifferentiated retinal pigment epithelial cells are immunoreactive for vascular endothelial growth factor in surgically excised age-related macular degeneration-related choroidal neovascular membranes," Investigative Ophthalmology and Visual Science, vol. 37, no. 5, pp. 855-868, 1996.

[83] M. Lu, M. Kuroki, S. Amano, et al., "Advanced glycation end products increase retinal vascular endothelial growth factor expression," Journal of Clinical Investigation, vol. 101, no. 6, pp. 1219-1224, 1998.

[84] A. N. Witmer, G. F. J. M. Vrensen, C. J. F. Van Noorden, and R. O. Schlingemann, "Vascular endothelial growth factors and angiogenesis in eye disease," Progress in Retinal and Eye Research, vol. 22, no. 1, pp. 1-29, 2003.

[85] B. Wirostko, T. Y. Wong, and R. Simó, "Vascular endothelial growth factor and diabetic complications," Progress in Retinal and Eye Research, vol. 27, no. 6, pp. 608-621, 2008.

[86] M. D. Sternfeld, J. E. Robertson, G. D. Shipley, J. Tsai, and J. T. Rosenbaum, "Cultured human retinal pigment epithelial cells express basic fibroblast growth factor and its receptor," Current Eye Research, vol. 8, no. 10, pp. 1029-1037, 1989.

[87] L. M. Bost, A. E. Aotaki-Keen, and L. M. Hjelmeland, "Coexpression of FGF-5 and bFGF by the retinal pigment epithelium in vitro," Experimental Eye Research, vol. 55, no. 5, pp. 727-734, 1992.

[88] T. Kitaoka, L. M. Bost, H. Ishigooka, A. E. Aotaki-Keen, and L. M. Hjelmeland, "Increasing cell density down-regulates the expression of acidic FGF by human RPE cells in vitro," Current Eye Research, vol. 12, no. 11, pp. 993-999, 1993.

[89] L. M. Bosta, A. E. Aotaki-Keen, and L. M. Hjelmeland, "Cellular adhesion regulates bFGF gene expression in human retinal pigment epithelial cells," Experimental Eye Research, vol. 58, no. 5, pp. 545-552, 1994.

[90] T. Kitaoka, A. E. Aotaki-Keen, and L. M. Hjelmeland, "Distribution of FGF-5 in the rhesus macaque retina," Investigative Ophthalmology and Visual Science, vol. 35, no. 8, pp. 3189-3198, 1994.

[91] K. C. Dunn, A. D. Marmorstein, V. L. Bonilha, E. RodriguezBoulan, F. Giordano, and L. M. Hjelmeland, "Use of the ARPE-19 cell line as a model of RPE polarity: basolateral secretion of FGF5," Investigative Ophthalmology and Visual Science, vol. 39, no. 13, pp. 2744-2749, 1998.

[92] A. Kvanta, "Expression and secretion of transforming growth factor- $\beta$ in transformed and nontransformed retinal pigment epithelial cells," Ophthalmic Research, vol. 26, no. 6, pp. 361$367,1994$.

[93] M. Matsumoto, N. Yoshimura, and Y. Honda, "Increased production of transforming growth factor- $\beta 2$ from cultured human retinal pigment epithelial cells by photocoagulation," Investigative Ophthalmology and Visual Science, vol. 35, no. 13, pp. 4245-4252, 1994.

[94] H. Tanihara, M. Yoshida, M. Matsumoto, and N. Yoshimura, "Identification of transforming growth factor- $\beta$ expressed in cultured human retinal pigment epithelial cells," Investigative Ophthalmology and Visual Science, vol. 34, no. 2, pp. 413-419, 1993.

[95] D. M. Martin, D. Yee, and E. L. Feldman, "Gene expression of the insulin-like growth factors and their receptors in cultured human retinal pigment epithelial cells," Brain Research, vol. 12, no. 1-3, pp. 181-186, 1992.

[96] M. G. Slomiany and S. A. Rosenzweig, "Autocrine effects of IGF-I-induced VEGF and IGFBP-3 secretion in retinal pigment epithelial cell line ARPE-19," American Journal of Physiology, vol. 287, no. 3, pp. C746-C753, 2004.
[97] W. Cao, R. Wen, F. Li, M. M. Lavail, and R. H. Steinberg, "Mechanical injury increases bFGF and CNTF mRNA expression in the mouse retina," Experimental Eye Research, vol. 65, no. 2, pp. 241-248, 1997.

[98] N. Walsh, K. Valter, and J. Stone, "Cellular and subcellular patterns of expression of bFGF and CNTF in the normal and light stressed adult rat retina," Experimental Eye Research, vol. 72, no. 5, pp. 495-501, 2001.

[99] P. A. Campochiaro, S. F. Hackett, S. A. Vinores, et al., "Platelet-derived growth factor is an autocrine growth stimulator in retinal pigmented epithelial cells," Journal of Cell Science, vol. 107, no. 9, pp. 2459-2469, 1994.

[100] P. A. Campochiaro, R. Sugg, G. Grotendorst, and L. M. Hjelmeland, "Retinal pigment epithelial cells produce PDGFlike proteins and secrete them into their media," Experimental Eye Research, vol. 49, no. 2, pp. 217-227, 1989.

[101] P. Ahuja, A. R. Caffe, I. Holmqvist, et al., "Lens epitheliumderived growth factor (LEDGF) delays photoreceptor degeneration in explants of $\mathrm{rd} / \mathrm{rd}$ mouse retina," NeuroReport, vol. 12, no. 13, pp. 2951-2955, 2001.

[102] H. Wenkel and J. W. Streilein, "Evidence that retinal pigment epithelium functions as an immune-privileged tissue," Investigative Ophthalmology and Visual Science, vol. 41, no. 11, pp. 3467-3473, 2000.

[103] J. W. Streilein, N. Ma, H. Wenkel, T. F. Ng, and P. Zamiri, "Immunobiology and privilege of neuronal retina and pigment epithelium transplants," Vision Research, vol. 42, no. 4, pp. 487-495, 2002.

[104] K. Ishida, N. Panjwani, Z. Cao, and J. W. Streilein, "Participation of pigment epithelium in ocular immune privilege. 3 . Epithelia cultured from iris, ciliary body, and retina suppress T-cell activation by partially non-overlapping mechanisms," Ocular Immunology and Inflammation, vol. 11, no. 2, pp. 91105, 2003.

[105] J. P. Alexander, J. M. B. Bradley, J. D. Gabourel, and T. S. Acott, "Expression of matrix metalloproteinases and inhibitor by human retinal pigment epithelium," Investigative Ophthalmology and Visual Science, vol. 31, no. 12, pp. 25202528, 1990.

[106] A. Ruiz, P. Brett, and D. Bok, "TIMP-3 is expressed in the human retinal pigment epithelium," Biochemical and Biophysical Research Communications, vol. 226, no. 2, pp. 467-474, 1996.

[107] N. G. Della, P. A. Campochiaro, and D. J. Zack, "Localization of TIMP-3 mRNA expression to the retinal pigment epithelium," Investigative Ophthalmology and Visual Science, vol. 37, no. 9, pp. 1921-1924, 1996.

[108] L. C. Padgett, G.-M. Lui, Z. Werb, and M. M. Lavail, "Matrix metalloproteinase-2 and tissue inhibitor of metalloproteinase-1 in the retinal pigment epithelium and interphotoreceptor matrix: vectorial secretion and regulation," Experimental Eye Research, vol. 64, no. 6, pp. 927-938, 1997.

[109] W. Eichler, U. Friedrichs, A. Thies, C. Tratz, and P. Wiedemann, "Modulation of matrix metalloproteinase and TIMP1 expression by cytokines in human RPE cells," Investigative Ophthalmology and Visual Science, vol. 43, no. 8, pp. 27672773, 2002.

[110] J. H. Qi, Q. Ebrahem, N. Moore, et al., "A novel function for tissue inhibitor of metalloproteinases-3 (TIMP3): inhibition of angiogenesis by blockage of VEGF binding to VEGF receptor-2," Nature Medicine, vol. 9, no. 4, pp. 407-415, 2003.

[111] N. Ogata, L. Wang, N. Jo, et al., "Pigment epithelium derived factor as a neuroprotective agent against ischemic retinal 
injury," Current Eye Research, vol. 22, no. 4, pp. 245-252, 2001.

[112] W. Cao, J. Tombran-Tink, R. Elias, S. Sezate, D. Mrazek, and J. F. McGinnis, "In vivo protection of photoreceptors from light damage by pigment epithelium-derived factor," Investigative Ophthalmology and Visual Science, vol. 42, no. 7, pp. 1646-1652, 2001.

[113] K. C. Behling, E. M. Surace, and J. Bennett, "Pigment epithelium-derived factor expression in the developing mouse eye," Molecular Vision, vol. 8, pp. 449-454, 2002.

[114] M. M. Jablonski, J. Tombran-Tink, D. A. Mrazek, and A. Iannaccone, "Pigment epithelium-derived factor supports normal development of photoreceptor neurons and opsin expression after retinal pigment epithelium removal," Journal of Neuroscience, vol. 20, no. 19, pp. 7149-7157, 2000.

[115] Q. Huang, S. Wang, C. M. Sorenson, and N. Sheibani, "PEDF-deficient mice exhibit an enhanced rate of retinal vascular expansion and are more sensitive to hyperoxiamediated vessel obliteration," Experimental Eye Research, vol. 87, no. 3, pp. 226-241, 2008.

[116] M. S. Burns and M. J. Hartz, "The retinal pigment epithelium induces fenestration of endothelial cells in vivo," Current Eye Research, vol. 11, no. 9, pp. 863-873, 1992.

[117] W. G. Roberts and G. E. Palade, "Increased microvascular permeability and endothelial fenestration induced by vascular endothelial growth factor," Journal of Cell Science, vol. 108, no. 6, pp. 2369-2379, 1995.

[118] S. P. Becerra, R. N. Fariss, Y. Q. Wu, L. M. Montuenga, P. Wong, and B. A. Pfeffer, "Pigment epithelium-derived factor in the monkey retinal pigment epithelium and interphotoreceptor matrix: apical secretion and distribution," Experimental Eye Research, vol. 78, no. 2, pp. 223-234, 2004.

[119] H. G. T. Blaauwgeers, G. M. Holtkamp, H. Rutten, et al., "Polarized vascular endothelial growth factor secretion by human retinal pigment epithelium and localization of vascular endothelial growth factor receptors on the inner choriocapillaris: evidence for a trophic paracrine relation," American Journal of Pathology, vol. 155, no. 2, pp. 421-428, 1999.

[120] M. Lu, M. Kuroki, S. Amano, et al., "Advanced glycation end products increase retinal vascular endothelial growth factor expression," Journal of Clinical Investigation, vol. 101, no. 6, pp. 1219-1224, 1998.

[121] Y. Yao, M. Guan, X. Q. Zhao, and Y. F. Huang, "Downregulation of the pigment epithelium derived factor by hypoxia and elevated glucose concentration in cultured human retinal pigment epithelial cells," Zhonghua yi xue za zhi, vol. 83, no. 22, pp. 1989-1992, 2003.

[122] P. Brazeau, W. Vale, R. Burgus, et al., "Hypothalamic polypeptide that inhibits the secretion of immunoreactive pituitary growth hormone," Science, vol. 179, no. 4068, pp. 77-79, 1973.

[123] S. Reichlin, "Somatostatin. (First of two parts)," The New England Journal of Medicine, vol. 309, no. 24, pp. 1495-1501, 1983.

[124] Y. C. Patel, M. T. Greenwood, A. Warszynska, R. Panetta, and C. B. Srikant, "All five cloned human somatostatin receptors (hSSTR1-5) are functionally coupled to adenylyl cyclase," Biochemical and Biophysical Research Communications, vol. 198, no. 2, pp. 605-612, 1994.

[125] K. Yamaguchi, V. P. Gaur, A. W. Spira, and J. E. Turner, "Cellular localization of somatostatin mRNA in rat retina," Neuropeptides, vol. 17, no. 1, pp. 13-16, 1990.
[126] J. N. Larsen, "Somatostatin in the retina," Acta Ophthalmologica Scandinavica, no. 218, pp. 1-24, 1995.

[127] J. Johnson, D. W. Rickman, and N. C. Brecha, "Somatostatin and somatostatin subtype $2 \mathrm{~A}$ expression in the mammalian retina," Microscopy Research and Technique, vol. 50, no. 2, pp. 103-111, 2000.

[128] O. P. Rorstad, M. K. Senterman, K. M. Hoyte, and J. B. Martin, "Immunoreactive and biologically active somatostatinlike material in the human retina," Brain Research, vol. 199, no. 2, pp. 488-492, 1980.

[129] S. M. Sagar and P. E. Marshall, "Somatostatin-like immunoreactive material in associational ganglion cells of human retina," Neuroscience, vol. 27, no. 2, pp. 507-516, 1988.

[130] P. M. Van Hagen, G. S. Baarsma, C. M. Mooy, et al., "Somatostatin and somatostatin receptors in retinal diseases," European Journal of Endocrinology, vol. 143, supplement 1, pp. S43-S51, 2000.

[131] A. C. Lambooij, R. W. A. M. Kuijpers, E. G. R. Van Lichtenauer-Kaligis, et al., "Somatostatin receptor 2A expression in choroidal neovascularization secondary to agerelated macular degeneration," Investigative Ophthalmology and Visual Science, vol. 41, no. 8, pp. 2329-2335, 2000.

[132] L. Helboe and M. Moller, "Immunohistochemical localization of somatostatin receptor subtypes sst 1 and sst 2 in the rat retina," Investigative Ophthalmology and Visual Science, vol. 40, no. 10, pp. 2376-2382, 1999.

[133] D. D. Klisovic, M. S. O’Dorisio, S. E. Katz, et al., "Somatostatin receptor gene expression in human ocular tissues: RTPCR and immunohistochemical study," Investigative Ophthalmology and Visual Science, vol. 42, no. 10, pp. 2193-2201, 2001.

[134] D. Cervia, G. Casini, and P. Bagnoli, "Physiology and pathology of somatostatin in the mammalian retina: a current view," Molecular and Cellular Endocrinology, vol. 286, no. 1-2, pp. 112-122, 2008.

[135] R. Burgos, C. Mateo, A. Cantón, C. Hernández, J. Mesa, and R. Simó, "Vitreous levels of IGF-I, IGF binding protein 1, and IGF binding protein 3 in proliferative diabetic retinopathy: a case-control study," Diabetes Care, vol. 23, no. 1, pp. 80-83, 2000.

[136] C. Hernández, R. Burgos, A. Cantón, J. García-Arumí, R. M. Segura, and R. Simó, "Vitreous levels of vascular cell adhesion molecule and vascular endothelial growth factor in patients with proliferative diabetic retinopathy: a casecontrol study," Diabetes Care, vol. 24, no. 3, pp. 516-521, 2001.

[137] E. Carrasco, C. Hernández, A. Miralles, P. Huguet, J. Farrés, and R. Simó, "Lower somatostatin expression is an early event in diabetic retinopathy and is associated with retinal neurodegeneration," Diabetes Care, vol. 30, no. 11, pp. 29022908, 2007.

[138] J. Johnson, M. L. Caravelli, and N. C. Brecha, "Somatostatin inhibits calcium influx into rat rod bipolar cell axonal terminals," Visual Neuroscience, vol. 18, no. 1, pp. 101-108, 2001.

[139] A. Vasilaki, R. Gardette, J. Epelbaum, and K. Thermos, "NADPH-diaphorase colocalization with somatostatin receptor subtypes sst2A and sst2B in the retina," Investigative Ophthalmology and Visual Science, vol. 42, no. 7, pp. 16001609, 2001.

[140] A. Akopian, J. Johnson, R. Gabriel, N. Brecha, and P. Witkovsky, "Somatostatin modulates voltage-gated $\mathrm{K}^{+}$and $\mathrm{Ca}^{2+}$ currents in rod and cone photoreceptors of the 
salamander retina," Journal of Neuroscience, vol. 20, no. 3, pp. 929-936, 2000.

[141] N. Lake and Y. C. Patel, "Neurotoxic agents reduce retinal somatostatin," Brain Research, vol. 181, no. 1, pp. 234-236, 1980.

[142] T. S. Kern and A. J. Barber, "Retinal ganglion cells in diabetes," Journal of Physiology, vol. 586, no. 18, pp. 44014408, 2008.

[143] X. Luo, G. N. Lambrou, J. A. Sahel, and D. Hicks, "Hypoglycemia induces general neuronal death, whereas hypoxia and glutamate transport blockade lead to selective retinal ganglion cell death in vitro," Investigative Ophthalmology and Visual Science, vol. 42, no. 11, pp. 2695-2705, 2001.

[144] M. I. Davis, S. H. Wilson, and M. B. Grant, "The therapeutic problem of proliferative diabetic retinopathy: targeting somatostatin receptors," Hormone and Metabolic Research, vol. 33, no. 5, pp. 295-299, 2001.

[145] C. Ristori, M. E. Ferretti, B. Pavan, et al., "Adenylyl cyclase/cAMP system involvement in the antiangiogenic effect of somatostatin in the retina. Results from transgenic mice," Neurochemical Research, vol. 33, no. 7, pp. 1247-1255, 2008.

[146] M. Dal Monte, M. Cammalleri, D. Martini, G. Casini, and P. Bagnoli, "Antiangiogenic role of somatostatin receptor 2 in a model of hypoxia-induced neovascularization in the retina: results from transgenic mice," Investigative Ophthalmology and Visual Science, vol. 48, no. 8, pp. 3480-3489, 2007.

[147] S. H. Wilson, M. I. Davis, S. Caballero, and M. B. Grant, "Modulation of retinal endothelial cell behaviour by insulinlike growth factor I and somatostatin analogues: implications for diabetic retinopathy," Growth Hormone and IGF Research, vol. 11, supplement 1, pp. S53-S59, 2001.

[148] L. E. H. Smith, W. Shen, C. Perruzzi, et al., "Regulation of vascular endothelial growth factor-dependent retinal neovascularization by insulin-like growth factor-1 receptor," Nature Medicine, vol. 5, no. 12, pp. 1390-1395, 1999.

[149] B. Mallet, B. Vialettes, S. Haroche, et al., "Stabilisation of severe proliferative diabetic retinopathy by long-term treatment with SMS 201-995," Diabete et Metabolisme, vol. 18, no. 6, pp. 438-444, 1992.

[150] B. O. Boehm, G. K. Lang, P. M. Jehle, B. Feldmann, and G. E. Lang, "Octreotide reduces vitreous hemorrhage and loss of visual acuity risk in patients with high-risk proliferative diabetic retinopathy," Hormone and Metabolic Research, vol. 33, no. 5, pp. 300-306, 2001.

[151] A. Baldysiak-Figiel, G. K. Lang, J. Kampmeier, and G. E. Lang, "Octreotide prevents growth factor-induced proliferation of bovine retinal endothelial cells under hypoxia," Journal of Endocrinology, vol. 180, no. 3, pp. 417-424, 2004.

[152] R. Simó, A. Lecube, L. Sararols, et al., "Deficit of somatostatin-like immunoreactivity in the vitreous fluid of diabetic patients. Possible role in the development of proliferative diabetic retinopathy," Diabetes Care, vol. 25, no. 12, pp. 2282-2286, 2002.

[153] C. Hernández, E. Carrasco, R. Casamitjana, R. Deulofeu, J. García-Arumí, and R. Simó, "Somatostatin molecular variants in the vitreous fluid: a comparative study between diabetic patients with proliferative diabetic retinopathy and nondiabetic control subjects," Diabetes Care, vol. 28, no. 8, pp. 1941-1947, 2005.

[154] R. Simó, E. Carrasco, A. Fonollosa, J. García-Arumí, R. Casamitjana, and C. Hernández, "Deficit of somatostatin in the vitreous fluid of patients with diabetic macular edema," Diabetes Care, vol. 30, no. 3, pp. 725-727, 2007.
[155] C. Hernández and R. Simó, "Strategies for blocking angiogenesis in diabetic retinopathy: from basic science to clinical practice," Expert Opinion on Investigational Drugs, vol. 16, no. 8, pp. 1209-1226, 2007.

[156] J. W. Fisher, "Erythropoietin: physiology and pharmacology update," Experimental Biology and Medicine, vol. 228, no. 1, pp. 1-14, 2003.

[157] H. H. Marti, "Erythropoietin and the hypoxic brain," Journal of Experimental Biology, vol. 207, no. 18, pp. 3233-3242, 2004.

[158] S. E. Juul, A. T. Yachnis, and R. D. Christensen, "Tissue distribution of erythropoietin and erythropoietin receptor in the developing human fetus," Early Human Development, vol. 52, no. 3, pp. 235-249, 1998.

[159] C. Hernández, A. Fonollosa, M. García-Ramírez, et al., "Erythropoietin is expressed in the human retina and it is highly elevated in the vitreous fluid of patients with diabetic macular edema," Diabetes Care, vol. 29, no. 9, pp. 2028-2033, 2006.

[160] M. García-Ramírez, C. Hernández, and R. Simó, "Expression of erythropoietin and its receptor in the human retina: a comparative study of diabetic and nondiabetic subjects," Diabetes Care, vol. 31, no. 6, pp. 1189-1194, 2008.

[161] W. Jelkmann, "Effects of erythropoietin on brain function," Current Pharmaceutical Biotechnology, vol. 6, no. 1, pp. 6579, 2005.

[162] S. P. Becerra and J. Amaral, "Erythropoietin-an endogenous retinal survival factor," The New England Journal of Medicine, vol. 347, no. 24, pp. 1968-1970, 2002.

[163] M. Kawakami, M. Sekiguchi, K. Sato, S. Kozaki, and M. Takahashi, "Erythropoietin receptor-mediated inhibition of exocytotic glutamate release confers neuroprotection during chemical ischemia," Journal of Biological Chemistry, vol. 276, no. 42, pp. 39469-39475, 2001.

[164] M. Yamasaki, H. K. Mishima, H. Yamashita, et al., "Neuroprotective effects of erythropoietin on glutamate and nitric oxide toxicity in primary cultured retinal ganglion cells," Brain Research, vol. 1050, no. 1-2, pp. 15-26, 2005.

[165] L. Danielyan, L. Mueller, B. Proksch, et al., "Similar protective effects of BQ-123 and erythropoietin on survival of neural cells and generation of neurons upon hypoxic injury," European Journal of Cell Biology, vol. 84, no. 11, pp. 907-913, 2005.

[166] A. K. Junk, A. Mammis, S. I. Savitz, et al., "Erythropoietin administration protects retinal neurons from acute ischemiareperfusion injury," Proceedings of the National Academy of Sciences of the United States of America, vol. 99, no. 16, pp. 10659-10664, 2002.

[167] E. Kilic, U. Kilic, J. Soliz, C. L. Bassetti, M. Gassmaim, and D. M. Hermann, "Brain-derived erythropoietin protects from focal cerebral ischemia by dual activation of ERK-1/-2 and Akt pathways," The FASEB Journal, vol. 19, no. 14, pp. 20262028, 2005.

[168] D. Agnello, P. Bigini, P. Villa, et al., "Erythropoietin exerts an anti-inflammatory effect on the CNS in a model of experimental autoimmune encephalomyelitis," Brain Research, vol. 952, no. 1, pp. 128-134, 2002.

[169] O. M. Martínez-Estrada, E. Rodríguez-Millan, E. Gonzalezde Vicente, M. Reina, S. Vilaro, and M. Fabre, "Erythropoietin protects the in vitro blood-brain barrier against VEGFinduced permeability," European Journal of Neuroscience, vol. 18, no. 9, pp. 2538-2544, 2003.

[170] K.-I. Hosoya and M. Tomi, "Advances in the cell biology of transport via the inner blood-retinal barrier: establishment 
of cell lines and transport functions," Biological and Pharmaceutical Bulletin, vol. 28, no. 1, pp. 1-8, 2005.

[171] E. A. Friedman, F. A. L'Esperance Jr., C. D. Brown, and D. H. Berman, "Treating azotemia-induced anemia with erythropoietin improves diabetic eye disease," Kidney International, Supplement, vol. 64, no. 87, pp. S57-S63, 2003.

[172] Y. Katsura, T. Okano, K. Matsuno, et al., "Erythropoietin is highly elevated in vitreous fluid of patients with proliferative diabetic retinopathy," Diabetes Care, vol. 28, no. 9, pp. 22522254, 2005.

[173] D. Watanabe, K. Suzuma, S. Matsui, et al., "Erythropoietin as a retinal angiogenic factor in proliferative diabetic retinopathy," The New England Journal of Medicine, vol. 353, no. 8, pp. 782-792, 2005.

[174] C. Grimm, A. Wenzel, M. Groszer, et al., "HIF-1-induced erythropoietin in the hypoxic retina protects against lightinduced retinal degeneration," Nature Medicine, vol. 8, no. 7, pp. 718-724, 2002.

[175] Y. Inomata, A. Hirata, E. Takahashi, T. Kawaji, M. Fukushima, and H. Tanihara, "Elevated erythropoietin in vitreous with ischemic retinal diseases," NeuroReport, vol. 15, no. 5, pp. 877-879, 2004.

[176] K. Jaquet, K. Krause, M. Tawakol-Khodai, S. Geidel, and K.H. Kuck, "Erythropoietin and VEGF exhibit equal angiogenic potential," Microvascular Research, vol. 64, no. 2, pp. 326333, 2002.

[177] J. Garcí-Arumí, A. Fonollosa, C. MacI, et al., "Vitreous levels of erythropoietin in patients with macular oedema secondary to retinal vein occlusions: a comparative study with diabetic macular oedema," Eye, vol. 23, no. 5, pp. 1066-1071, 2009.

[178] J. Zhang, Y. Wu, Y. Jin, et al., "Intravitreal injection of erythropoietin protects both retinal vascular and neuronal cells in early diabetes," Investigative Ophthalmology and Visual Science, vol. 49, no. 2, pp. 732-742, 2008.

[179] B. Zhu, W. Wang, Q. Gu, and X. Xu, "Erythropoietin protects retinal neurons and glial cells in early-stage streptozotocininduced diabetic rats," Experimental Eye Research, vol. 86, no. 2, pp. 375-382, 2008.

[180] J. C. Dreixler, S. Hagevik, J. W. Hemmert, A. R. Shaikh, D. M. Rosenbaum, and S. Roth, "Involvement of erythropoietin in retinal ischemic preconditioning," Anesthesiology, vol. 110, no. 4, pp. 774-780, 2009.

[181] J. Chen, K. M. Connor, C. M. Aderman, and L. E. H. Smith, "Erythropoietin deficiency decreases vascular stability in mice," Journal of Clinical Investigation, vol. 118, no. 2, pp. 526-533, 2008.

[182] A. E. Gawad, L. Schlichting, O. Strauß, and O. Zeitz, "Antiapoptotic properties of erythropoietin: novel strategies for protection of retinal pigment epithelial cells," Eye, vol. 23, no. 10, pp. 2245-2250, 2009.

[183] H. Chung, H. Lee, F. Lamoke, W. J. M. Hrushesky, P. A. Wood, and W. J. Jahng, "Neuroprotective role of erythropoietin by antiapoptosis in the retina," Journal of Neuroscience Research, vol. 87, no. 10, pp. 2365-2374, 2009.

[184] G. Grasso, F. Graziano, A. Sfacteria, et al., "Neuroprotective effect of erythropoietin and darbepoetin alfa after experimental intracerebral hemorrhage," Neurosurgery, vol. 65, no. 4, pp. 763-769, 2009.

[185] Z.-Y. Wang, L.-J. Shen, L. Tu, et al., "Erythropoietin protects retinal pigment epithelial cells from oxidative damage," Free Radical Biology and Medicine, vol. 46, no. 8, pp. 1032-1041, 2009.

[186] C. Heeschen, A. Aicher, R. Lehmann, et al., "Erythropoietin is a potent physiologic stimulus for endothelial progenitor cell mobilization," Blood, vol. 102, no. 4, pp. 1340-1346, 2003.

[187] S. Brunner, G. H. Schernthaner, M. Satler, et al., "Correlation of different circulating endothelial progenitor cells to stages of diabetic retinopathy: first in vivo data.," Investigative Ophthalmology \& Visual Science, vol. 50, no. 1, pp. 392-398, 2009.

[188] S. Caballero, N. Sengupta, A. Afzal, et al., "Ischemic vascular damage can be repaired by healthy, but not diabetic, endothelial progenitor cells," Diabetes, vol. 56, no. 4, pp. 960967, 2007.

[189] M. B. Grant, M. E. Boulton, and A. V. Ljubimov, "Erythropoietin: when liability becomes asset in neurovascular repair," Journal of Clinical Investigation, vol. 118, no. 2, pp. 467-470, 2008.

[190] N. Tserentsoodol, N. V. Gordiyenko, I. Pascual, J. W. Lee, S. J. Fliesler, and I. R. Rodriguez, "Intraretinal lipid transport is dependent on high density lipoprotein-like particles and class B scavenger receptors," Molecular Vision, vol. 12, pp. 13191333, 2006.

[191] R. Simó, M. Higuera, M. García-Ramírez, F. Canals, J. GarcíaArumí, and C. Hernández, "Elevation of apolipoprotein A$\mathrm{I}$ and apolipoprotein $\mathrm{H}$ levels in the vitreous fluid and overexpression in the retina of diabetic patients," Archives of Ophthalmology, vol. 126, no. 8, pp. 1076-1081, 2008.

[192] R. Simó, M. García-Ramírez, M. Higuera, and C. Hernández, "Apolipoprotein A1 is overexpressed in the retina of diabetic patients," American Journal of Ophthalmology, vol. 147, no. 2, pp. 319-325.e1, 2009.

[193] C.-M. Li, M. E. Clark, M. F. Chimento, and C. A. Curcio, "Apolipoprotein localization in isolated drusen and retinal apolipoprotein gene expression," Investigative Ophthalmology and Visual Science, vol. 47, no. 7, pp. 3119-3128, 2006.

[194] N. Tserentsoodol, J. Sztein, M. Campos, et al., "Uptake of cholesterol by the retina occurs primarily via a low density lipoprotein receptor-mediated process," Molecular Vision, vol. 12, pp. 1306-1318, 2006.

[195] K. C. Hayes, S. Lindsey, Z. F. Stephan, and D. Brecker, "Retinal pigment epithelium possesses both LDL and scavenger receptor activity," Investigative Ophthalmology and Visual Science, vol. 30, no. 2, pp. 225-232, 1989.

[196] K. G. Duncan, K. R. Bailey, J. P. Kane, and D. M. Schwartz, "Human retinal pigment epithelial cells express scavenger receptors BI and BII," Biochemical and Biophysical Research Communications, vol. 292, no. 4, pp. 1017-1022, 2002.

[197] S. Kawai, T. Nakajima, S. Hokari, T. Komoda, and K. Kawai, "Apolipoprotein A-I concentration in tears in diabetic retinopathy," Annals of Clinical Biochemistry, vol. 39, no. 1, pp. 56-61, 2002.

[198] R. Simó and C. Hernández, "Fenofibrate for diabetic retinopathy," The Lancet, vol. 370, no. 9600, pp. 1667-1668, 2007.

[199] B. Y. Ishida, K. G. Duncan, K. R. Bailey, J. P. Kane, and D. M. Schwartz, "High density lipoprotein mediated lipid efflux from retinal pigment epithelial cells in culture," British Journal of Ophthalmology, vol. 90, no. 5, pp. 616-620, 2006.

[200] M. I. Mackness and P. N. Durrington, "HDL, its enzymes and its potential to influence lipid peroxidation," Atherosclerosis, vol. 115, no. 2, pp. 243-253, 1995.

[201] F. Robbesyn, N. Augé, C. Vindis, et al., "High-density lipoproteins prevent the oxidized low-density lipoproteininduced endothelial growth factor receptor activation and subsequent matrix metalloproteinase-2 upregulation," Arteriosclerosis, Thrombosis, and Vascular Biology, vol. 25, no. 6, pp. 1206-1212, 2005. 
[202] D. S. Ng, L. A. Leiter, C. Vezina, P. W. Connelly, and R. A. Hegele, "Apolipoprotein A-I Q[-2]X causing isolated apolipoprotein A-I deficiency in a family with analphalipoproteinemia," Journal of Clinical Investigation, vol. 93, no. 1, pp. 223-229, 1994.

[203] D. S. Ng, P. W. O’Connor, C. B. Mortimer, L. A. Leiter, P. W. Connelly, and R. A. Hegele, "Retinopathy and neuropathy associated with complete apolipoprotein A-I deficiency," American Journal of the Medical Sciences, vol. 312, no. 1, pp. 30-33, 1996.

[204] C. A. Curcio, C. L. Millican, T. Bailey, and H. S. Kruth, "Accumulation of cholesterol with age in human Bruch's membrane," Investigative Ophthalmology and Visual Science, vol. 42, no. 1, pp. 265-274, 2001.

[205] C.-M. Li, M. E. Clark, M. F. Chimento, and C. A. Curcio, "Apolipoprotein localization in isolated drusen and retinal apolipoprotein gene expression," Investigative Ophthalmology and Visual Science, vol. 47, no. 7, pp. 3119-3128, 2006. 

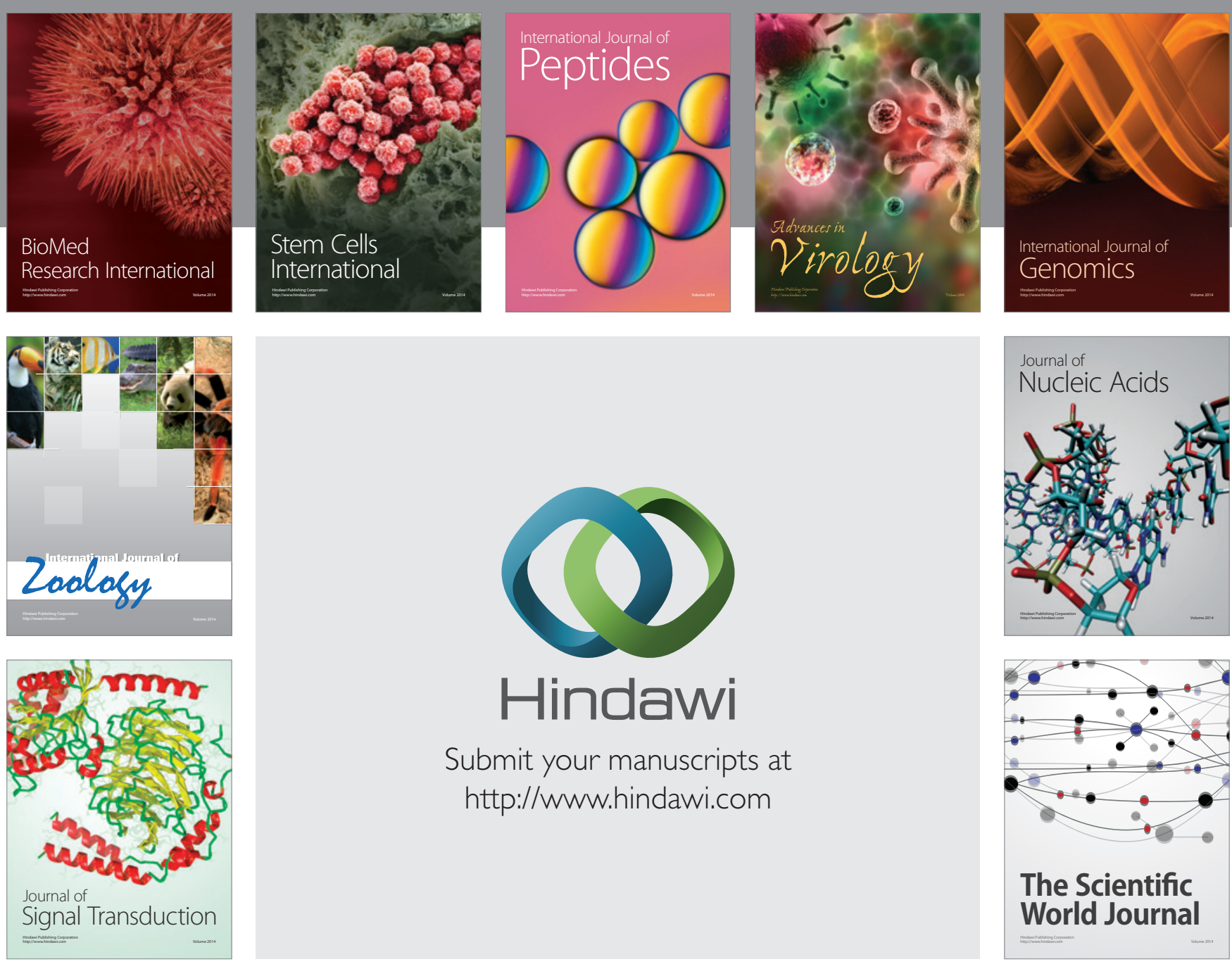

Submit your manuscripts at

http://www.hindawi.com
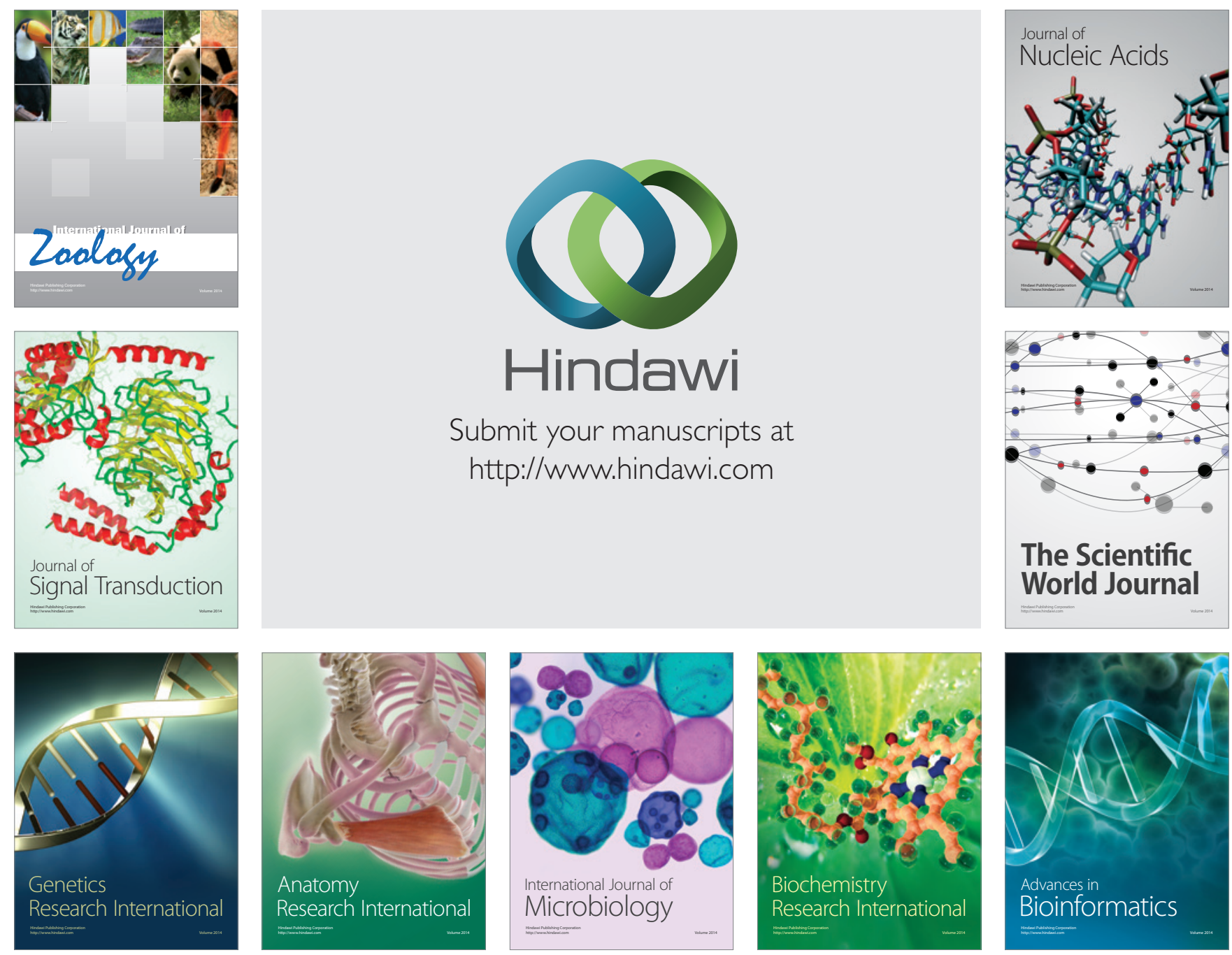

The Scientific World Journal
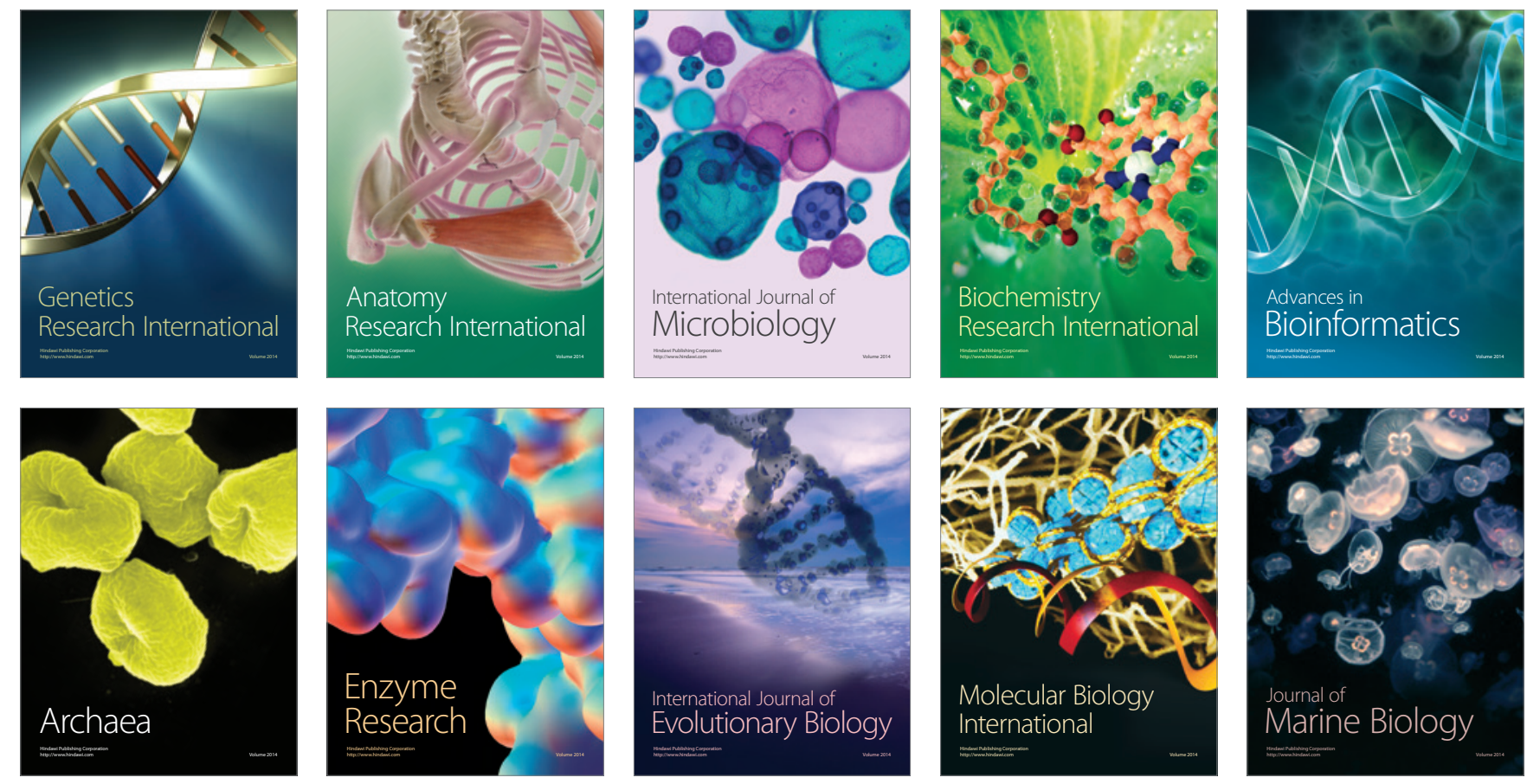